\title{
TODIM Dynamic Emergency Decision-Making Method Based on Hybrid Weighted Distance Under Probabilistic Hesitant Fuzzy Information
}

\author{
Quanyu Ding $^{1,2} \cdot$ Ying-Ming Wang ${ }^{1,3} \cdot$ Mark Goh $^{2}$
}

Received: 24 September 2019/Revised: 25 September 2020/ Accepted: 30 September 2020/Published online: 5 February 2021

(C) Taiwan Fuzzy Systems Association 2021

\begin{abstract}
The classical TODIM method solves problems by expressing the attribute values as crisp numbers, thus incurring information loss. This paper, noting the ambiguity and fuzziness of information especially in a probabilistic hesitant fuzzy environment, develops a TODIM dynamic emergency decision-making method based on hybrid weighted distance. This method is suitable for emergency decision-making as it supports the rapidity and evolving nature of emergency responses, and accommodates the uncertainty of the external environment. A case study of a huge fire in China is used to validate the proposed method. The proposed TODIM method outperforms the methods proposed by Gao et al. in Int. J. Fuzzy. Syst. 19(5), 1261-1278 (2017) and Zhang et al. in Syst. 61, 48-58 (2014), suggesting its appeal in dealing with fuzzy information during emergency decision-making.
\end{abstract}

Quanyu Ding

N180710002@fzu.edu.cn

Ying-Ming Wang

ymwang@fzu.edu.cm

Mark Goh

bizgohkh@nus.edu.sg

1 Decision Sciences Institute, Fuzhou University, Fuzhou, Fujian 350116, People's Republic of China

2 NUS Business School and the Logistics Institute-Asia Pacific, National University of Singapore, Singapore, Singapore

3 Key Laboratory of Spatial Data Mining \& Information Sharing of Ministry of Education, Fuzhou University, Fuzhou, Fujian 350116, People's Republic of China
Keywords Probabilistic hesitant fuzzy set - TODIM . Hybrid weighted distance - Emergency decision-making . China

\section{Introduction}

Large-scale, high-risk but infrequent disasters at the provincial, national, and regional levels have wrought severe consequences to society $[1,2]$. Some examples of such events include the Liangshan forest fire in Sichuan in 2019 resulting in the unnecessary deaths of 30 firefighters, the great Australian bushfire in 2020 in three Australian states, depleting 46 million acres of land, destroying 6000 farms, decimating half a billion native animals and unnecessary lives lost, and the COVID-19, which led to severe health and economic impacts globally with half a million fatalities. In all three disasters, emergency response decisions were needed at the national, regional, municipal, and firm levels. The decision-makers and stakeholders had to decide on the necessary courses of action and craft appropriate responses to bring the situation back to normalcy as quickly as possible, despite not fully knowing the extent of the collateral damage nor what will happen next in the emergency. Therefore, knowing how to make a decision quickly and accurately during an emergency response is now an agenda on many a decision-maker's plates globally. The study of Emergency Decision-Making (EDM), and the establishment and improvement of an emergency response system are now a principal consideration when formulating national policy, especially in Asia. In the case of the public sector departments providing incomplete or inaccurate information, time urgency, and other uncontrollable externalities, EDM indeed has challenges on many fronts [3]. For instance, in China, natural 
disasters are frequent, causing millions of deaths each year, leading to unnecessary economic loss, and hindering social development. Therefore, when a disaster occurs, the key question is to how to shorten the first response (i.e., EDM) and to select a reasonable emergency alternative to minimize the immediate losses [4-7]. In this regard, many studies have called for knowledge- and rule-based decision support systems. However, decision support systems often need to choose the best emergency plan based on many attributes. Therefore, EDM problems belong to the class of Multi-Attribute Decision-Making (MADM) problems [8]. Most works on EDM involve MADM, group decisionmaking (GDM), game theory, case reasoning technique, scenario construction, etc., as shown in Table 1.

Although the researches on emergency management are rich, they presupposes that the decision-maker (DM) is completely rational [17]. However, many studies have shown that DMs are bounded rational under the conditions of risk and uncertainty $[9,10,18]$. The DMs usually have a psychological expectation and are more sensitive to losses than gains [19]. With the irregularity in emergencies, the problem of emergency response veers more towards tackling the risks and uncertainties. Therefore, the psychological behavior of the DMs must be considered in the DM process. Most studies focused on prospect theory when considering the psychological behavior of the DMs [18]. However, a decision-making method based on prospect theory has an inherent limitation: the level of expectation needs to be known a priori, which is difficult to achieve.

Hence, this paper seeks to address this limitation by developing a distance measurement method based on the TODIM (an acronym in Portuguese of interactive and multiple attribute decision-making) method [20]. Compared with prospect theory, the advantage of the TODIM method is that the decision-making outcome is determined by computing the degree of gain or loss of an alternative relative to the rest, to better reflect the behavioral preference of the DMs such as reference dependence and loss aversion. At present, TODIM method has been extended to handle various types of fuzzy information, such as interval type-2 fuzzy information [21], triangular intuitionistic fuzzy numbers [22], Pythagorean uncertainty fuzzy linguistic information [23], interval numbers [24], probabilistic linguistic term sets [25] and so forth. It is undeniable that all hesitant fuzzy sets have their unique advantages. The reason why we choose probabilistic hesitant fuzzy sets is the evolution of emergency events, the change in the complex external environment, and other factors that have an impact on the EDM process. Therefore, we have to consider the probability of the change in the external environment. Probabilistic hesitant fuzzy sets accommodate more information uncertainty and reflect the preference of the DMs better.

Different from the other MADM problems such as supplier selection [26], EDM problems usually have high risk and uncertainty, and implementing the wrong EDM choice may lead to serious social consequences. Therefore, in the context of an emergency, DMs should avoid obtaining conflicting solutions and strive for higher-quality decision-making in the EDM process. Typically, the framework of the EDM process has two phases: an evaluation phase and a selection phase (see Fig. 1). In the evaluation phase, DMs provide their individual evaluation information based on their professional knowledge, experience, and similar historical emergency events. In the selection phase, an evaluation method is implemented to assess the alternatives and select the best course of action.

Although the researches on EDM have contributed to better emergency management $[3,9,10]$, however, most of the related EDM methods assume that the decision-makers are psychological behavior independent and ignore the influence of the probability of occurrence in the external environment. Therefore, we develop a dynamic TODIM EDM method for emergencies in a probabilistic hesitant fuzzy environment, addressing two concerns:

1. Sometimes, the information to base the evaluation is supplied by a DM. Thus, noting the psychology of the DMs who provide the information can improve the decision-making outcomes. This is especially when the DMs operate in a complex and uncertain decision environment. So far, few studies apply the hybrid weighted distance using probabilistic hesitant fuzzy

Table 1 Related studies on EDM

\begin{tabular}{lll}
\hline Background & Methods & Literature \\
\hline Coal mine explosion Barrier Lake Emergency & MADM & [3, 9, 10] \\
Explosions at Tianjin Port Selection of emergency shelter after earthquake & GDM & [11, 12] \\
Improving emergency response capability & Scenario construction & Game theory \\
Settings for emergency exits & Case-based reasoning & {$[13]$} \\
Man-made disaster situations post-disaster emergency resource planning & {$[15,16]$} \\
\hline
\end{tabular}




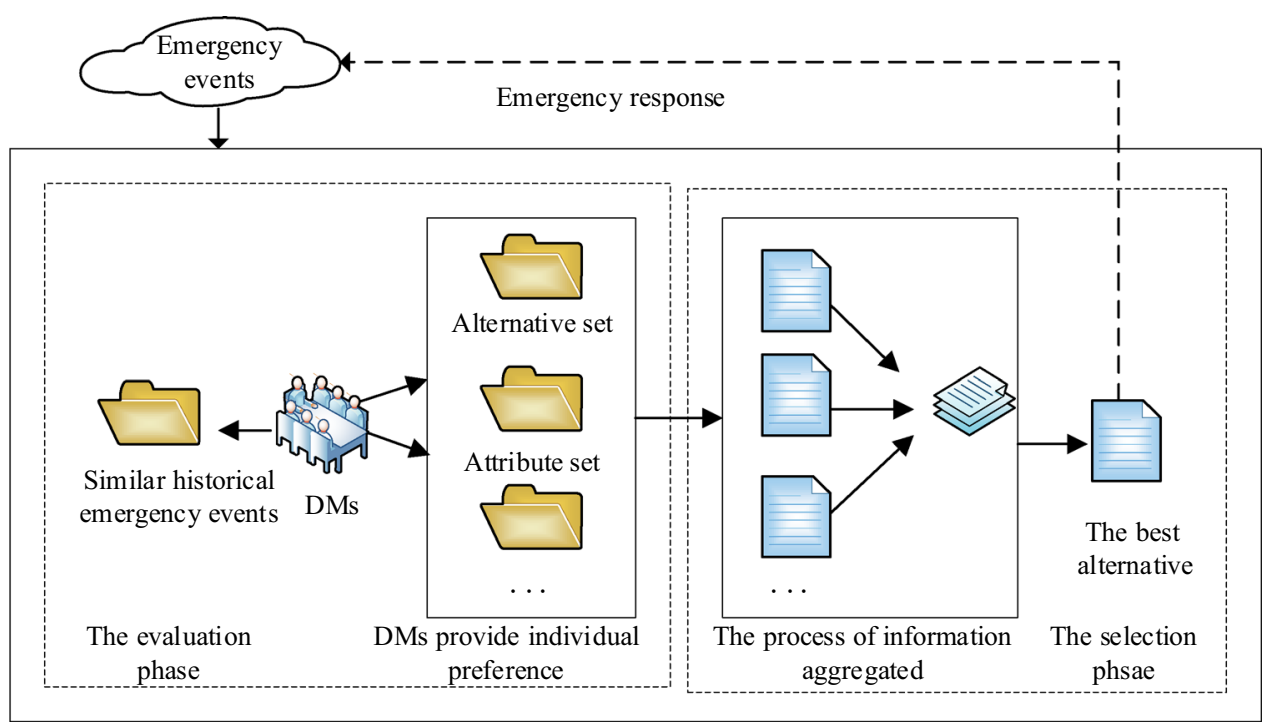

Fig. 1 Framework of EDM process

information to handle emergencies considering the DM's psychological behavior.

2. Many researchers have tried to present different discussions about the EDM with hesitant fuzzy sets, albeit the management of other hesitant fuzzy sets in EDM has been done by using ranking models that present limitations. No study has used the TODIM method with an EDM approach based on a hybrid weighted distance under a probabilistic hesitant fuzzy environment. Thus, this paper will supply a realistic ranking method for a probabilistic hesitant fuzzy set that recognizes and facilitates the rapidly evolving EDM process.

Furthermore, our proposed method can simulate an actual emergency environment, avoid information distortion or attenuation, provide policy support for the DMs, and provide robust solutions to complex large-scale emergencies, to minimize the loss of lives and livelihood.

The rest of this paper is as follows: Sect. 2 presents some preliminaries. Section 3 develops a new probabilistic hesitant fuzzy hybrid weighted distance (PHFHWD) measure. Section 4 proposes a TODIM dynamic emergency decision-making method based on hybrid weighted distance under probabilistic hesitant fuzzy information. In Sect. 5, an example to evaluate the emergency response alternatives to the explosions at Tianjin Port is used to validate the proposed method. Section 6 concludes.

\section{Preliminaries}

This section introduces some preliminaries that will be used in the future sections, which include problem background, probabilistic hesitant fuzzy sets (PHFSs), and the classical TODIM method.

\subsection{Description of the Emergency Problem}

When an emergency event occurs, it is usually dynamic and rapidly changing, fraught with much dissonance and uncertainty. At time $t_{r}$, the DMs can only obtain fuzzy information about the emergency from the first responders who sounded the alert. However, due to the sudden and urgent situation, the DMs can only make a preliminary assessment and act based on the history of similar emergencies, and personal experience. At time $t_{r+1}$, the emergency decision made at time $t_{r}$ would have been implemented in the interim. The DMs would need to decide on the measures to take in the next period based on the on-site information and the situation on the ground. For instance, unexpected strong winds may force an almost under control bush fire to change course and wreak havoc in a new locale, which may house more residents than expected. As such, the DMs have to modify the emergency response to obtain the best outcome. Hence, the DM, despite being affected by the change in external circumstance and already psychologically affected, has to decide when to re-select an emergency response. In short, the DMs have to dynamically adjust their decisions based on the latest available information to achieve the best emergency response outcome, as shown in Fig. 2. 


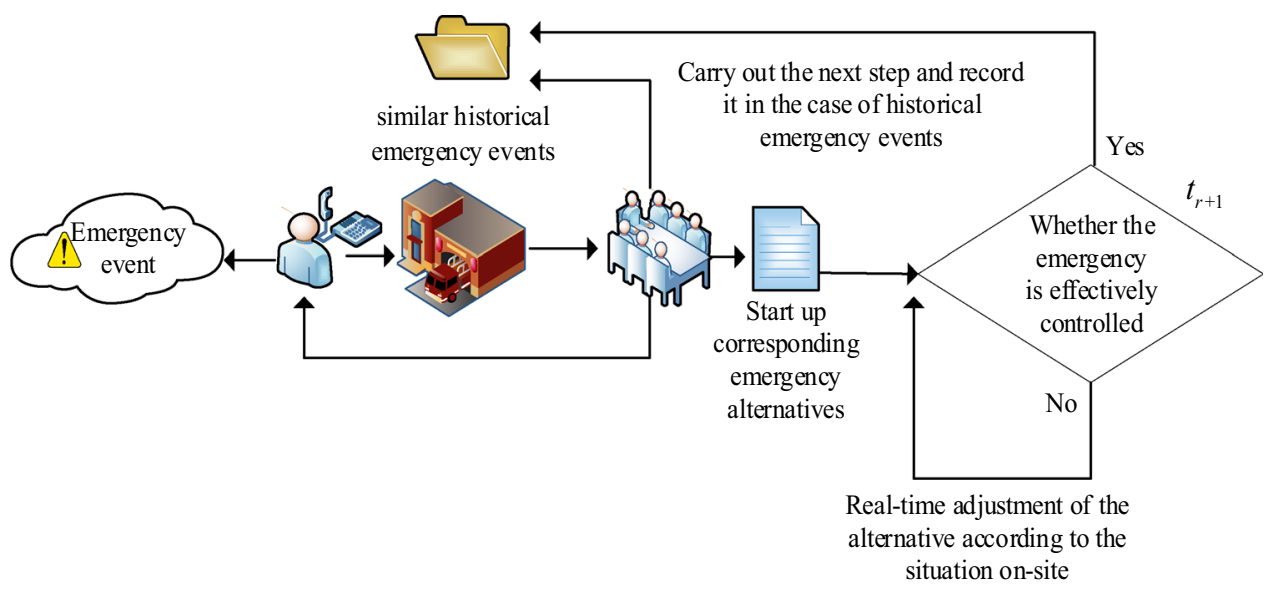

Fig. 2 Dynamic adjustment process of emergency alternative

\subsection{Probabilistic Hesitant Fuzzy}

Definition 1 [27] Let $R$ be a fixed set, and then a PHFS $H_{p}$ on $R$ is represented in term of the following mathematical symbol:

$H_{p}=\left\{h\left(\gamma_{i} \mid p_{i}\right) \mid \gamma_{i}, p_{i}\right\}$,

where $h\left(\gamma_{i} \mid p_{i}\right)$ is a set of some probabilistic hesitant fussy elements (PHFEs) $\gamma_{i} \mid p_{i}, \gamma_{i} \in R, 0 \leq \gamma_{i} \leq 1, i=1,2, \cdots, l_{h}$, and $l_{h}$ is the number of elements in $h\left(\gamma_{i} \mid p_{i}\right)$ (we denote it as $h(p)$ for short $), \gamma_{i}$ denotes the possible membership degrees of the element $x \in H_{p}$, and $\gamma_{i} \in[0,1] . p_{i} \in[0,1]$ is the occurrence probability of $\gamma_{i}$, and $\sum_{i=1}^{l_{h}} p_{i} \leq 1$. If $\sum_{i=1}^{l_{h}} p_{i}$ $<1$, the PHFS is deemed incomplete. The complement of $h\left(\gamma_{i} \mid p_{i}\right)$ given by $h^{\mathrm{C}}\left(\gamma_{i} \mid p_{i}\right)=\left\{\left(\left(1-\gamma_{i}\right) \mid p_{i}\right) \mid i=1\right.$, $\left.2, \cdots, l_{h}\right\}$.

Definition 2 [27] Let arbitrary $h(\bar{p})=\left\{\gamma_{i}\left|p_{i}\right| i=1,2\right.$, $\cdots, l\}$ be the normalized PHFE, and $\overline{p_{i}}=p_{i} / \sum_{i=1}^{l_{h}} p_{i}$.

Definition 3 [28] For a PHFN $h(\bar{p})=\left\{\gamma_{i}\left|p_{i}\right| i=1,2\right.$, $\cdots, l\}$, the score and deviation functions of $h(p)$ are defined, respectively, as

$s(h(p))=\sum_{i=1}^{l_{h}} \gamma_{i} p_{i}$

$v(h(p))=\sum_{i=1}^{l_{j}} p_{i}\left(s(h(p))-\gamma_{i}\right)^{2}$.

If $s\left(h_{1}(p)\right)>s\left(h_{2}(p)\right)$, then $h_{1}(p)>h_{2}(p)$;

If $s\left(h_{1}(p)\right)<s\left(h_{2}(p)\right)$, then $h_{1}(p)<h_{2}(p)$;

If $s\left(h_{1}(p)\right)=s\left(h_{2}(p)\right)$, then

(1) if $v\left(h_{1}(p)\right)>v\left(h_{2}(p)\right)$, then $h_{1}(p)>h_{2}(p)$;

(2) if $v\left(h_{1}(p)\right)<v\left(h_{2}(p)\right)$, then $h_{1}(p)<h_{2}(p)$;

(3) if $v\left(h_{1}(p)\right)=v\left(h_{2}(p)\right)$, then $h_{1}(p)=h_{2}(p)$.
Definition 4 [29] Let $h_{1}(p)$ and $h_{2}(p)$ be two arbitrary PHFNs, then the probabilistic hesitant fuzzy Hamming distance between $h_{1}(p)$ and $h_{2}(p)$ is defined as:

$d\left(h_{1}(p), h_{2}(p)\right)=\sum_{i=1}^{l}\left|\gamma_{i}^{1} p_{i}^{1}-\gamma_{i}^{2} p_{i}^{2}\right|$.

\subsection{The Classical TODIM Method}

To facilitate analysis and subsequent extensions, the classical TODIM method [20], which is on the base of prospect theory, is briefly introduced below.

Let $A=\left\{A_{1}, A_{2}, \cdots, A_{\mathrm{n}}\right\}$ be a set of alternatives, where $A_{i}(i=1,2, \cdots, n)$ denotes $i$ th alternative. Let $C=$ $\left\{C_{1}, C_{2}, \cdots, C_{m}\right\}$ be a set of attributes, where $C_{j}(j=1,2, \cdots, m)$ denotes $j$ th attribute. Let $\omega=\left(\omega_{1}\right.$, $\left.\omega_{2}, \cdots \omega_{m}\right)^{\mathrm{T}}$ be a vector of attribute weights, where $\omega_{j}\left(\omega_{j} \in[0,1], \sum_{j=1}^{m} \omega_{j}=1\right)$ denotes the weight of attribute $C_{j}$. The algorithmic for the classic TODIMmethod is as follows:

Step 2.3.1: Form the decision matrix $X=\left[x_{i j}\right]_{n \times m}$ comprising $n$ alternatives and $m$ evaluation attributes.

Step 2.3.2: Normalize the decision matrix $X=\left[x_{i j}\right]_{n \times m}$ into $\bar{X}=\left[\bar{x}_{i j}\right]_{n \times m}$, according to the cost and benefits attribute. This renders the decision matrix dimensionless and the matrix elements comparable.

Step 2.3.3: Calculate the relative weight $\omega_{j r}=\omega_{j} / \omega_{r}$, where $\omega_{r}=\max \left\{\omega_{j}, j=1,2, \cdots, n\right\}$.

Step 2.3.4: The dominance degree $\phi_{j}\left(A_{i}, A_{q}\right)$ of alternative $A_{i}$ over alternative $A_{q}$ for the attribute $C_{j}$ is calculated. 


$$
\left\{\begin{array}{cc}
\phi_{j}\left(A_{i}, A_{q}\right)= & \begin{array}{cc}
\sqrt{\omega_{j r}\left(d_{i j}-d_{q j}\right) / \sum_{j=1}^{m} \omega_{j r},} & d_{i j}-d_{q j}>0 \\
0, & d_{i j}-d_{q j}=0 \\
-\frac{1}{\theta} \sqrt{\sum_{j=1}^{m} \omega_{j r} \times\left(d_{q j}-d_{i j}\right) / \omega_{j r},} & d_{i j}-d_{q j}<0,
\end{array}
\end{array}\right.
$$

where $\theta$ is the attenuation coefficient of the losses. If $d_{i j}-d_{q j}>0\left(d_{i j}-d_{q j}<0\right)$, then $d_{i j}-d_{q j}$ represents the gain (loss) of alternative $A_{i}$ over alternative $A_{q}$ for the attribute.

Step 2.3.5: The comprehensive dominance degree $\phi\left(A_{i}, A_{q}\right)$ of alternative $A_{i}$ over the alternative $A_{q}$ is found from

$$
\phi\left(A_{i}, A_{q}\right)=\sum_{j=1}^{m} \phi_{j}\left(A_{i}, A_{q}\right), \quad i, q=1, \cdots, n .
$$

Step 2.3.6: The overall dominance value $\Phi\left(A_{i}\right)$ of alternative $A_{i}$ is obtained according to

$$
\Phi\left(A_{i}\right)=\frac{\sum_{q=1}^{n} \phi\left(A_{i}, A_{q}\right)-\min \sum_{q=1}^{n} \phi\left(A_{i}, A_{q}\right)}{\max \sum_{q=1}^{n} \phi\left(A_{i}, A_{q}\right)-\min \sum_{q=1}^{n} \phi\left(A_{i}, A_{q}\right)} .
$$

Step 2.3.7: The alternatives are then ranked in descending order, based on their scores. We choose the highest (i.e., maximum dominance score) as the best choice.

\section{Probabilistic Hesitant Fuzzy Hybrid Weighted Distance}

Definition 5 Let $H_{p 1}=\left\{h\left(\gamma_{i} \mid p_{i}\right) \mid \gamma_{i}, p_{i}\right\} \quad$ and $H_{p 2}=$ $\left\{h\left(\gamma_{i} \mid p_{i}\right) \mid \gamma_{i}, p_{i}\right\}$ are two PHFSs, then the probabilistic hesitant fuzzy weighted distance (PHFWD) between $H_{p 1}$ and $H_{p 2}$ is given by:

$$
\begin{aligned}
& \operatorname{PHFWD}\left(\mathrm{H}_{\mathrm{p} 1}, \mathrm{H}_{\mathrm{p} 2}\right) \\
& =\left(\sum_{j=1}^{m} \omega_{j}\left(d_{p}\left(h_{1}\left(\gamma_{i} \mid p_{i}\right), h_{2}\left(\gamma_{i} \mid p_{i}\right)\right)\right)^{\lambda}\right)^{\frac{1}{\lambda}},
\end{aligned}
$$

where $\omega_{j}(j=1,2, \cdots, m)^{\mathrm{T}}$ is a weight vector, with $\omega_{j} \in[0,1], \sum_{j=1}^{m} \omega_{j}=1$. Sometimes, the number of elements in $H_{p 1}$ is not equal to the number of elements in $H_{p 2}$, i.e., $l_{H_{p 1}} \neq l_{H_{p 2}}$. In this paper, the risk attitude of the DMs is used to determine which added element will make the length of two PHFE's equal. For this, we set $h_{i}^{+}=$ $\max \left\{\gamma_{i} p_{i}\right\}$ and $h_{i}^{-}=\min \left\{\gamma_{i} p_{i}\right\}$. If the DM is risk neutral, the added element is $h=0.5 \times\left(h_{i}^{+}+h_{i}^{-}\right)$. If the DM is risk averse (seeker), the added element is $h=h_{i}^{-}\left(h=h_{i}^{+}\right)$.

Furthermore, when $\lambda=1$, the PHFWD measure is reduced to the probabilistic hesitant fuzzy weighted Hamming distance (PHFWHD) measure. When $\lambda=2$, then the PHFWD measure is reduced to the probabilistic hesitant fuzzy weighted Euclidean distance (PHFWED) measure. The PHFWD measure only considers the importance of the PHFEs, but not the importance of their position.

Definition 6 Let $H_{p 1}=\left\{h\left(\gamma_{i} \mid p_{i}\right) \mid \gamma_{i}, p_{i}\right\}$ and $H_{p 2}=$ $\left\{h\left(\gamma_{i} \mid p_{i}\right) \mid \gamma_{i}, p_{i}\right\}$ are two PHFSs, and the probabilistic hesitant fuzzy ordered weighted distance (PHFOWD) between $H_{p 1}$ and $H_{p 2}$ has the following form:

$\operatorname{PHFOWD}\left(\mathrm{H}_{\mathrm{p} 1}, \mathrm{H}_{\mathrm{p} 2}\right)$

$$
=\left(\sum_{j=1}^{\max \left(l_{H_{p 1}}, l_{H_{p 2}}\right)} w_{j}\left(d_{p}\left(h_{\sigma(j)_{1}}\left(\gamma_{i} \mid p_{i}\right), h_{\sigma(j)_{2}}\left(\gamma_{i} \mid p_{i}\right)\right)\right)^{\lambda}\right)^{\frac{1}{\lambda}},
$$

where $w_{j}(j=1,2, \cdots, m)^{\mathrm{T}}$ is an order weight vector, with $w_{j} \in[0,1], \quad \sum_{j=1}^{m} w_{j}=1 . \quad "(\sigma(1), \sigma(2), \cdots, \sigma(j))$ " is the order of " $(1,2, \cdots, j)$ ", such as $\sigma(j)$ is the $j$ th largest PHFE among the PHFS. In particular, when $\lambda=1$, then the PHFOWD measure is reduced to the probabilistic hesitant fuzzy ordered weighted Hamming distance (PHFOWHD) measure; when $\lambda=2$, then then the PHFWD measure is reduced to the probabilistic hesitant fuzzy ordered weighted Euclidean distance (PHFOWED) measure.

Clearly, from definitions 5 and 6 , the weight of the PHFWD measure stresses on the importance of the evaluation attribute while the weight of the PHFOWD measure stresses on the importance of the position of the attribute. However, both distance measures (i.e., PHFWD and PHFOWD) can only consider a single aspect of weight, but not both. Therefore, we propose a probabilistic hesitant fuzzy hybrid weighted distance (PHFHWD) measure.

Definition 7 Let $H_{p 1}=\left\{h\left(\gamma_{i} \mid p_{i}\right) \mid \gamma_{i}, p_{i}\right\}$ and $H_{p 2}=$ $\left\{h\left(\gamma_{i} \mid p_{i}\right) \mid \gamma_{i}, p_{i}\right\}$ be two PHFSs, and the probabilistic hesitant fuzzy hybrid weighted distance (PHFHWD) between $H_{p 1}$ and $H_{p 2}$ is given by:

$$
\begin{aligned}
& \operatorname{PHFHWD}\left(\mathrm{H}_{\mathrm{p} 1}, \mathrm{H}_{\mathrm{p} 2}\right) \\
& =\left(\sum_{j=1}^{m} w_{j}\left(\tilde{d}_{p}\left(h_{\sigma(j)_{1}}\left(\gamma_{i} \mid p_{i}\right), h_{\sigma(j)_{2}}\left(\gamma_{i} \mid p_{i}\right)\right)\right)^{\lambda}\right)^{\frac{1}{\lambda}},
\end{aligned}
$$

where $\tilde{d}_{p}\left(h_{\sigma(j)_{1}}\left(\gamma_{i} \mid p_{i}\right), h_{\sigma(j)_{2}}\left(\gamma_{i} \mid p_{i}\right)\right)$ is the $j$ th largest element among $\tilde{d}_{p}\left(h_{1}\left(\gamma_{i} \mid p_{i}\right), \quad h_{2}\left(\gamma_{i} \mid p_{i}\right)\right) . \quad \tilde{d}_{p}\left(h_{1}\left(\gamma_{i} \mid p_{i}\right), h_{2}\left(\gamma_{i} \mid p_{i}\right)\right)=$ 
$n \omega_{j} \operatorname{PHFWD}\left(\mathrm{h}_{1}\left(\gamma_{\mathrm{i}} \mid \mathrm{p}_{\mathrm{i}}\right), \mathrm{h}_{2}\left(\gamma_{\mathrm{i}} \mid \mathrm{p}_{\mathrm{i}}\right)\right)$, where $w_{j}(j=1,2, \cdots, m)$ is the weight vector of PHFHWD measure, and $w_{j} \in[0,1]$, $\sum_{j=1}^{m} w_{j}=1$.

Similarly, when $\lambda=1$, the PHFOWD measure is reduced to the probabilistic hesitant fuzzy hybrid weighted Hamming distance (PHFHWHD) measure; when $\lambda=2$, then the PHFWD measure is reduced to the probabilistic hesitant fuzzy hybrid weighted Euclidean distance (PHFHWED) measure.

Theorem 1 PHFWD and PHFOWD measures are special cases of PHFHWD measure.

Proof Set $w=\left(\frac{1}{n}, \frac{1}{n}, \cdots, \frac{1}{n}\right)^{\mathrm{T}}$ and $\lambda=1$, then

$\operatorname{PHFHWD}\left(\mathrm{H}_{\mathrm{p} 1}, \mathrm{H}_{\mathrm{p} 2}\right)$

$$
\begin{aligned}
& =\left(\sum_{j=1}^{\max \left(l_{H_{p 1}}, l_{l_{p 2}}\right)} w_{j}\left(\tilde{d}_{p}\left(h_{\sigma(j)_{1}}\left(\gamma_{i} \mid p_{i}\right), h_{\sigma(j)_{2}}\left(\gamma_{i} \mid p_{i}\right)\right)\right)^{\lambda}\right)^{\frac{1}{\lambda}} \\
& =\left(\sum_{j=1}^{\max \left(l_{H_{p 1}}, l_{H_{p 2}}\right)} \frac{1}{n}\left(n \omega_{j} \operatorname{PHFWD}\left(\mathrm{h}_{1}\left(\gamma_{\mathrm{i}} \mid \mathrm{p}_{\mathrm{i}}\right), \mathrm{h}_{2}\left(\gamma_{\mathrm{i}} \mid \mathrm{p}_{\mathrm{i}}\right)\right)\right)^{\lambda}\right)^{\frac{1}{\lambda}} \\
& =\left(\sum_{j=1}^{\max \left(l_{H_{p 1}}, l_{H_{p 2}}\right)}\left(\omega_{j} \operatorname{PHFWD}\left(\mathrm{h}_{1}\left(\gamma_{\mathrm{i}} \mid \mathrm{p}_{\mathrm{i}}\right), \mathrm{h}_{2}\left(\gamma_{\mathrm{i}} \mid \mathrm{p}_{\mathrm{i}}\right)\right)\right)^{\lambda}\right)^{\frac{1}{\lambda}} \\
& =\operatorname{PHFWD}\left(\mathrm{H}_{\mathrm{p} 1}, \mathrm{H}_{\mathrm{p} 2}\right) .
\end{aligned}
$$

Furthermore, $\omega=\left(\frac{1}{n}, \frac{1}{n}, \cdots, \frac{1}{n}\right)^{\mathrm{T}}$, then

$\operatorname{PHFHWD}\left(\mathrm{H}_{\mathrm{p} 1}, \mathrm{H}_{\mathrm{p} 2}\right)$

$$
\begin{aligned}
& =\left(\sum_{j=1}^{\max \left(l_{l_{p 1}}, l_{H_{p 2}}\right)} w_{j}\left(\tilde{d}_{p}\left(h_{\sigma(j)_{1}}\left(\gamma_{i} \mid p_{i}\right), h_{\sigma(j)_{2}}\left(\gamma_{i} \mid p_{i}\right)\right)\right)^{\lambda}\right)^{\frac{1}{\lambda}} \\
& =\left(\sum_{j=1}^{\max \left(l_{H_{p 1}}, l_{H_{p 2}}\right)} w_{j}\left(n \frac{1}{n} \operatorname{PHFWD}\left(\mathrm{h}_{\sigma(\mathrm{j})_{1}}\left(\gamma_{\mathrm{i}} \mid \mathrm{p}_{\mathrm{i}}\right), \mathrm{h}_{\sigma(\mathrm{j})_{2}}\left(\gamma_{\mathrm{i}} \mid \mathrm{p}_{\mathrm{i}}\right)\right)\right)^{\lambda}\right)^{\frac{1}{\lambda}} \\
& =\operatorname{PHFOWD}\left(\mathrm{H}_{\mathrm{p} 1}, \mathrm{H}_{\mathrm{p} 2}\right) .
\end{aligned}
$$

It can be seen that the PHFHWD measure is an extension of PHFWD measure and PDFHWD measure, which not only considers the importance of each attribute, but also considers the importance of the position of the attribute.

\section{TODIM Dynamic Emergency Decision-Making Method Based on Hybrid Weighted Distance Under Probabilistic Hesitant Fuzzy Information}

We now provide the notation used to develop the 9-step method proposed in this paper. And the related definition of a framework is as follows (see Fig. 3).

Notations

$Z=\left\{Z_{1}, Z_{2}, \cdots, Z_{q}\right\} \quad$ Potential state of an emergency in time $(t=1, \cdots, q), Z_{t}(t=1, \cdots, q)$ denotes the state $Z_{t}$ under the time $t$.

$A=\left\{A_{1}, A_{2}, \cdots, A_{\mathrm{n}}\right\} \quad$ Refers to emergency alternative $A_{i}(i=1, \cdots, n)$. If an emergency situation does not require any action, $A$ become an empty set $\varnothing \subseteq A$.

$C=\left\{C_{1}, C_{2}, \cdots, C_{m}\right\} \quad$ The set of attributes given by DMs according to the emergency, where $C_{j}$ means the $j$ th attribute, and $j=1, \cdots, m$.

$\omega=\left\{\omega_{1}, \omega_{2}, \cdots, \omega_{m}\right\} \quad$ Weight of attribute, where $\sum_{i=1}^{m} \omega_{i}=1$ and $\omega_{i} \in[0,1]$.

$w=\left\{w_{1}, w_{2}, \cdots, w_{m}\right\} \quad$ Ordered weight of the attribute after ranking, with $\sum_{i=1}^{m} w_{i}=1$ and $w_{i} \in[0,1]$.

$e=\left\{e_{1}, e_{2}, \cdots, e_{s}\right\} \quad$ Set of DMs responding to an emergency, where $e_{1}$ is the $l$ th $\mathrm{DM}, l=1, \cdots, s$.

$\omega_{\mathrm{e}}=\left\{\omega_{e_{1}}, \omega_{e_{2}}, \cdots, \omega_{e_{s}}\right\} \quad$ Weight of DMs, with $\sum_{e=1}^{s} \omega_{\mathrm{e}}=1$ and $\omega_{\mathrm{e}} \in[0,1]$.

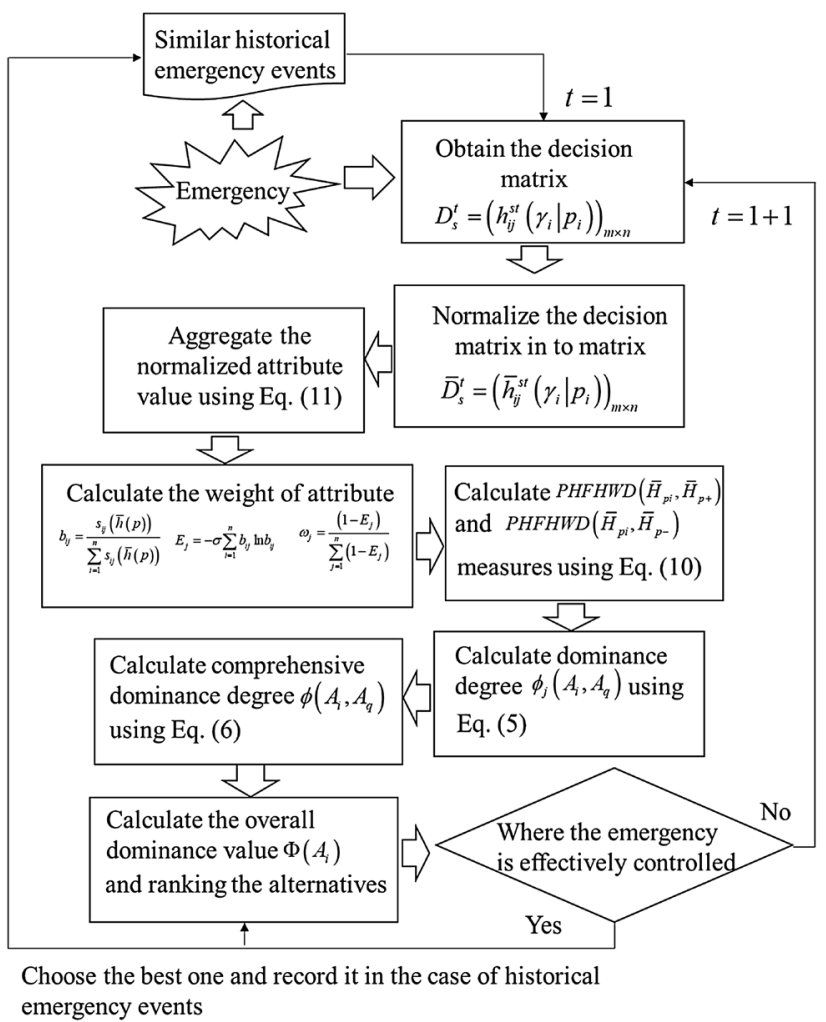

Fig. 3 Emergency decision-making process in this paper 
Before handling emergency incidents, we check the relevant records to sight similar past emergencies. If such records exist, we refer to how such emergencies were handled, to deal with the current situation. Otherwise, the DMs should discuss and craft a response. Next, we kick start the emergency response procedure. The evaluation value of an emergency can vary with time, depending on the severity of the situation. To make a dynamic decision based on the evaluation value given by the DMs at different instances, we call on the following steps:

Step 1: The DMs evaluate alternative $A_{i}$ on attribute $C_{j}$, given that emergency state $Z_{t}(t=1)$ occurs. The evaluation results are expressed by PHFE $h_{i j}^{s t}\left(\gamma_{i} \mid p_{i}\right)$, and then the decision matrix $D_{s}^{t}=\left(h_{i j}^{s t}\left(\gamma_{i} \mid p_{i}\right)\right)_{m \times n}$ is obtained.

Step 2: Normalize $D_{s}^{t}=\left(h_{i j}^{s t}\left(\gamma_{i} \mid p_{i}\right)\right)_{m \times n}$ into matrix $\overline{D_{s}^{t}}=\left(\bar{h}_{i j}^{s t}\left(\gamma_{i} \mid p_{i}\right)\right)_{m \times n}$. An attribute is either cost of a benefit attribute. Suppose the normalized attribute value is $\bar{h}_{i j}^{s t}\left(\gamma_{i} \mid p_{i}\right)$, then the normalized benefit attribute is $\bar{h}_{i j}^{s t}\left(\gamma_{i} \mid p_{i}\right)=h_{i j}^{s t}\left(\gamma_{i} \mid p_{i}\right)$, the normalized cost attribute is $\bar{h}_{i j}^{s t}\left(\gamma_{i} \mid p_{i}\right)=h_{i j}^{s t}\left(\left(1-\gamma_{i}\right) \mid p_{i}\right)$, respectively.

Step 3: Aggregate the normalized attribute value using Eq. (11):

$$
\begin{aligned}
& \operatorname{PHFWA}\left(\mathrm{h}_{\mathrm{ij}}^{1 \mathrm{t}}\left(\gamma_{\mathrm{ij}} \mid \mathrm{p}_{\mathrm{ij}}\right), \mathrm{h}_{\mathrm{ij}}^{2 \mathrm{ti}}\left(\gamma_{\mathrm{ij}} \mid \mathrm{p}_{\mathrm{ij}}\right), \cdots, \mathrm{h}_{\mathrm{ij}}^{\mathrm{st}}\left(\gamma_{\mathrm{ij}} \mid \mathrm{p}_{\mathrm{ij}}\right)\right) \\
& =\bigoplus_{k=1}^{\mathrm{s}}\left(\omega_{e k} h_{i j}^{k t}\left(\gamma_{i j} \mid p_{i j}\right)\right) \\
& \quad=\bigcup_{\gamma_{i j}^{1 t} \in p_{i j}^{1 t}, \gamma_{i j}^{2 t} \in \in_{i j}^{2 t}, \cdots, \gamma_{i j}^{s t} \in p_{i j}^{s t}} \\
& \quad\left\{1-\prod_{k=1}^{s}\left(1-\gamma_{i j}^{k t}\right)^{\omega_{e_{k}}} \mid p_{i j}^{1 t} p_{i j}^{2 t} \cdots p_{i j}^{s t}\right\} .
\end{aligned}
$$

Step 4: Find the weight of attributes. In this paper, the score function and the entropy weight method [30] are combined to find the weight of attributes:

$$
\begin{aligned}
b_{i j} & =\frac{s_{i j}(\bar{h}(p))}{\sum_{i=1}^{n} s_{i j}(\bar{h}(p))}, \\
E_{j} & =-\sigma \sum_{i=1}^{n} b_{i j} \ln b_{i j}, \\
\omega_{j} & =\frac{\left(1-E_{j}\right)}{\sum_{j=1}^{n}\left(1-E_{j}\right)},
\end{aligned}
$$

where $\sigma=\frac{1}{\ln n}, 0 \leq E_{j} \leq 1$.

Step 5: Obtain PHFHWD $\left(\mathrm{H}_{\mathrm{pi}}, \mathrm{H}_{\mathrm{p}+}\right)$ and PHFHWD $\left(\bar{H}_{p i}, \bar{H}_{p-}\right)$ measures using Eq. $(10)$, where $\bar{H}_{p+}$ and $\bar{H}_{p-}$ are the probabilistic hesitant fuzzy positive ideal solution (PHFPIS) and probabilistic hesitant fuzzy negative ideal solution (PHFNIS), respectively.

Step 6: Find dominance degree $\phi_{j}\left(A_{i}, A_{q}\right)$ of alternative $A_{i}$ over alternative $A_{q}$ for attribute $C_{j}$ using Eq. (5).
Step 7: Compute the comprehensive dominance degree $\phi\left(A_{i}, A_{q}\right)$ of alternative $A_{i}$ over alternative $A_{q}$ for attribute $C_{j}$ using Eq. (6).

Step 8: Compute the overall dominance value $\Phi\left(A_{i}\right)$ of alternative $A_{i}$, and ranking the alternatives according to $\Phi\left(A_{i}\right)$. The larger $\Phi\left(A_{i}\right)$ is, the better is alternative $A_{i}$.

Step 9: Is the effectively under control. If yes, end the procedure. Choose the highest dominant score solution, and record it in the case of historical emergency events. If not, $t=t+1$, go to step 1 .

\section{Case Study}

To validate the proposed method, we consider the series of large explosions that occurred in Tianjin City Port in China on August 12, 2015 (source).

A massive fire broke out in a dangerous goods chemicals warehouse of Ruihai Company in Tianjin Port, and the emergency department responded immediately. Due to the complexity of the scene, and the tight rescue timeline, the responders did not know enough about the quantity of the contents in the warehouse, the impact of the fire, nor the degree of toxicity of the chemicals. Therefore, an improper formulation of an on-site rescue plan could cause harm to the rescue workers, seriously threatening the safety of the rescue workers and the surrounding facilities. The top command department, based on experience, proposed to suspend the on-site rescue plan, and called for an EDM based on the emergency situation. Due to the seriousness of the situation and the urgency of time, an expert panel of four DMs (each DM has the same weight) formulated the following emergency responses for consideration:

$A_{1}$ : Evacuate people from the vicinity of the Port to a safe zone and inform the people in potentially dangerous areas to be ready to evacuate at any time and lock down the city. Next, request Beijing and Hebei province fire department for 5 unmanned aerial vehicles, 45 fire engines, and 17 chemical disaster rescue and disposal teams.

$A_{2}$ : Evacuate people from the vicinity of the port to a safe zone and inform the people in the city to prepare for possible evacuation, and setup partial roadblocks. Next, request Beijing and Hebei province fire department to send 4 unmanned aerial vehicles, 40 fire engines, and 17 chemical disaster rescue and disposal teams.

$A_{3}$ : Transfer people from the vicinity of the port to a safe zone and inform the people in the city to prepare for possible evacuation. At the same time, request Beijing, Jiangsu, Liaoning, and Hebei provinces fire department to send 4 unmanned aerial vehicles, 43 fire engines, and 19 chemical disaster rescue and disposal teams. 
The DMs proposed five attributes for the emergency rescue work after observing analyzing the fire situation on the scene, combining with similar historical cases, their professional knowledge and referring to the "Code for Classification and Coding of Emergency Events":

$C_{1}$ : Possibility of more explosions during the rescue (due to the flammability of the goods)

$C_{2}$ : Weather conditions at the time of rescue (presence of strong winds)

$C_{3}$ : Ease of rescue (any blockages to the warehouse)

$C_{4}$ : Timeliness of rescue (before the heat becomes too strong for rescue work)

$C_{5}$ : Cost of rescue (potential lives lost).

From the analysis of the experts, the rescue and chemicals disposal team, and the weather reports, the port may encounter three situations or states in the next $72 \mathrm{~h}$ :

$Z_{1}$ : in the $t_{1}$ stage, the weather becomes cloudy and the light southwest breeze will blow the gaseous emissions from the dangerous goods towards the Bohai Sea. With a sea breeze, the fire may intensify, widening the area of the blaze. As the specific explosive is unknown, a high probability of re-explosion in the stage cannot be discounted.
$Z_{2}$ : in the $t_{2}$ stage, a thunderstorm may occur and a strong southwest wind will blow the gaseous emissions from the dangerous goods towards the Bohai Sea. While a thunderstorm may dampen the fire, the DMs are not certain if the thunderstorm can quench the fire. However, because cyanide is a water-soluble toxic substance, it will be affected by a thunderstorm. There is also the concern of Cyanide dissolved in water leaking into the city.

$Z_{3}$ : in the $t_{3}$ stage, the weather is clear, the southwest breeze will disperse the gaseous emissions from the dangerous goods towards the Bohai Sea, which is helpful for the diffusion of the contaminant in the air. Depending on the success of the previous fire-fighting work, the fire may be under control. Suppose the specific explosives are identified. It is necessary to enter the explosion site with biochemical troops for search and rescue and hazardous chemical cleaning.

\subsection{Decision Steps}

Step 1: The DMs evaluate alternative $A_{i}$ given that a certain state $Z_{t}$ has occurred concerning attribute $C_{j}$ and the data

Table 2 Evaluation values of alternatives in state $Z_{1}$

\begin{tabular}{|c|c|c|c|c|c|c|}
\hline \multirow[t]{2}{*}{ DM } & \multirow[t]{2}{*}{ Alternative } & \multicolumn{5}{|l|}{ Attribute } \\
\hline & & $C_{1}$ & $C_{2}$ & $C_{3}$ & $C_{4}$ & $C_{5}$ \\
\hline \multirow[t]{3}{*}{$e_{1}$} & $A_{1}$ & $(0.84 \mid 1.0)$ & $(0.66 \mid 1.0)$ & $(0.65|0.4,0.86| 0.2)$ & $(0.69 \mid 0.5)$ & $(0.69|0.4,0.79| 0.4)$ \\
\hline & $A_{2}$ & $(0.86|0.4,0.79| 0.5)$ & $(0.76|0.4,0.79| 0.5)$ & $(0.76 \mid 0.4)$ & $(0.81|0.4,0.82| 0.3)$ & $(0.81 \mid 0.4)$ \\
\hline & $A_{3}$ & $(0.89|0.5,0.79| 0.3)$ & $(0.82 \mid 1.0)$ & $(0.76 \mid 1.0)$ & $\begin{array}{l}(0.89|0.5,0.79| 0.3 \\
0.67 \mid 0.2)\end{array}$ & $(0.80 \mid 1.0)$ \\
\hline \multirow[t]{3}{*}{$e_{2}$} & $A_{1}$ & $(0.73 \mid 1.0)$ & $(0.82|0.4,0.72| 0.6)$ & $\begin{array}{l}(0.65|0.4,0.86| 0.4 \\
0.96 \mid 0.2)\end{array}$ & $(0.80 \mid 1.0)$ & $(0.82|0.6,0.76| 0.4)$ \\
\hline & $A_{2}$ & $\begin{array}{l}(0.76|0.4,0.69| 0.5 \\
0.86 \mid 0.1)\end{array}$ & $(0.76|0.4,0.69| 0.5)$ & $(0.86|0.4,0.79| 0.5)$ & $(0.76 \mid 1.0)$ & $(0.81 \mid 0.4)$ \\
\hline & $A_{3}$ & $(0.69|0.4,0.59| 0.6)$ & $\begin{array}{l}(0.76|0.4,0.69| 0.5 \\
0.86 \mid 0.1)\end{array}$ & $\begin{array}{l}(0.69|0.3,0.76| 0.6 \\
0.88 \mid 0.2)\end{array}$ & $(0.66|0.5,0.73| 0.5)$ & $(0.62 \mid 1.0)$ \\
\hline \multirow[t]{3}{*}{$e_{3}$} & $A_{1}$ & $(0.49 \mid 1.0)$ & $(0.52|0.4,0.62| 0.6)$ & $(0.78|0.6,0.89| 0.4)$ & $\begin{array}{l}(0.69|0.3,0.76| 0.5 \\
0.88 \mid 0.2)\end{array}$ & $\begin{array}{l}(0.87|0.3,0.67| 0.6 \\
0.93 \mid 0.2)\end{array}$ \\
\hline & $A_{2}$ & $(0.69|0.6,0.59| 0.4)$ & $(0.65 \mid 1.0)$ & $(0.89|0.6,0.92| 0.3)$ & $(0.79|0.3,0.68| 0.5)$ & $\begin{array}{l}(0.82|0.3,0.73| 0.6 \\
0.63 \mid 0.1)\end{array}$ \\
\hline & $A_{3}$ & $(0.63|0.3,0.66| 0.4)$ & $\begin{array}{l}(0.63|0.3,0.73| 0.4 \\
0.69 \mid 0.3)\end{array}$ & $(0.79|0.6,0.71| 0.4)$ & $(0.87|0.7,0.71| 0.3)$ & $(0.82|0.4,0.72| 0.6)$ \\
\hline \multirow[t]{3}{*}{$e_{4}$} & $A_{1}$ & $\begin{array}{l}(0.63|0.2,0.73| 0.6 \\
0.89 \mid 0.2)\end{array}$ & $(0.55|0.6,0.61| 0.4)$ & $(0.60|0.8,0.70| 0.2)$ & $(0.33|0.4,0.45| 0.6)$ & $\begin{array}{l}(0.63|0.3,0.73| 0.3 \\
0.89 \mid 0.4)\end{array}$ \\
\hline & $A_{2}$ & $(0.53|0.5,0.65| 0.5)$ & $\begin{array}{l}(0.40|0.3,0.55| 0.3, \\
0.69 \mid 0.4)\end{array}$ & $\begin{array}{l}(0.50|0.2,0.60| 0.3 \\
0.71 \mid 0.5)\end{array}$ & $(0.60|0.6,0.75| 0.2)$ & $(0.70|0.5,0.80| 0.5)$ \\
\hline & $A_{3}$ & $\begin{array}{l}(0.80|0.5,0.85| 0.3, \\
0.9 \mid 0.2)\end{array}$ & $\begin{array}{l}(0.35|0.2,0.44| 0.4 \\
0.50 \mid 0.4)\end{array}$ & $(0.56|0.2,0.66| 0.8)$ & $(0.50|0.4,0.65| 0.6)$ & $(0.62|0.3,0.75| 0.7)$ \\
\hline
\end{tabular}


Table 3 Evaluation values of alternative in state $Z_{2}$

\begin{tabular}{|c|c|c|c|c|c|c|}
\hline \multirow[t]{2}{*}{ DM } & \multirow[t]{2}{*}{ Alternative } & \multicolumn{5}{|l|}{ Attribute } \\
\hline & & $C_{1}$ & $C_{2}$ & $C_{3}$ & $C_{4}$ & $C_{5}$ \\
\hline \multirow[t]{3}{*}{$e_{1}$} & $A_{1}$ & $\begin{array}{l}(0.80|0.5,0.85| 0.3, \\
0.89 \mid 0.2)\end{array}$ & $(0.78|0.6,0.82| 0.2)$ & $\begin{array}{l}(0.68|0.4,0.75| 0.3 \\
0.89 \mid 0.3)\end{array}$ & $(0.50|0.5,0.67| 0.5)$ & $(0.73|0.4,0.87| 0.3)$ \\
\hline & $A_{2}$ & $(0.68|0.5,0.72| 0.5)$ & $(0.53|0.5,0.67| 0.5)$ & $(0.76|0.3,0.87| 0.7)$ & $\begin{array}{l}(0.50|0.3,0.60| 0.3 \\
0.70 \mid 0.4)\end{array}$ & $\begin{array}{l}(0.70|0.2,0.80| 0.2, \\
0.90 \mid 0.4)\end{array}$ \\
\hline & $A_{3}$ & $(0.76|0.4,0.79| 0.5)$ & $\begin{array}{l}(0.69|0.3,0.76| 0.6 \\
0.88 \mid 0.2)\end{array}$ & $(0.65 \mid 1.0)$ & $(0.80 \mid 1.0)$ & $(0.82|0.6,0.76| 0.4)$ \\
\hline \multirow[t]{3}{*}{$e_{2}$} & $A_{1}$ & $\begin{array}{l}(0.76|0.4,0.69| 0.5 \\
0.86 \mid 0.1)\end{array}$ & $(0.76|0.4,0.69| 0.5)$ & $(0.86|0.4,0.79| 0.5)$ & $(0.76 \mid 1.0)$ & $(0.81 \mid 0.4)$ \\
\hline & $A_{2}$ & $(0.53|0.5,0.77| 0.5)$ & $\begin{array}{l}(0.72|0.7,0.80| 0.2 \\
0.90 \mid 0.1)\end{array}$ & $\begin{array}{l}(0.53|0.2,0.60| 0.3 \\
0.74 \mid 0.5)\end{array}$ & $(0.63|0.6,0.71| 0.2)$ & $\begin{array}{l}(0.55|0.7,0.60| 0.2 \\
0.84 \mid 0.1)\end{array}$ \\
\hline & $A_{3}$ & $(0.51|0.4,0.63| 0.6)$ & $(0.63|0.7,0.70| 0.3)$ & $\begin{array}{l}(0.60|0.3,0.70| 0.4 \\
0.84 \mid 0.3)\end{array}$ & $(0.63|0.5,0.70| 0.5)$ & $\begin{array}{l}(0.50|0.7,0.60| 0.2, \\
0.84 \mid 0.1)\end{array}$ \\
\hline \multirow[t]{3}{*}{$e_{3}$} & $A_{1}$ & $(0.49 \mid 1.0)$ & $(0.52|0.4,0.62| 0.6)$ & $(0.78|0.6,0.89| 0.4)$ & $\begin{array}{l}(0.69|0.3,0.76| 0.5 \\
0.88 \mid 0.2)\end{array}$ & $\begin{array}{l}(0.87|0.3,0.67| 0.6 \\
0.93 \mid 0.2)\end{array}$ \\
\hline & $A_{2}$ & $(0.53|0.5,0.65| 0.5)$ & $\begin{array}{l}(0.40|0.3,0.55| 0.3 \\
0.69 \mid 0.4)\end{array}$ & $\begin{array}{l}(0.50|0.2,0.60| 0.3 \\
0.71 \mid 0.5)\end{array}$ & $(0.60|0.6,0.75| 0.2)$ & $(0.70|0.5,0.80| 0.5)$ \\
\hline & $A_{3}$ & $(0.63|0.3,0.66| 0.4)$ & $\begin{array}{l}(0.63|0.3,0.73| 0.4 \\
0.69 \mid 0.3)\end{array}$ & $(0.79|0.6,0.71| 0.4)$ & $(0.87|0.7,0.71| 0.3)$ & $(0.82|0.4,0.72| 0.6)$ \\
\hline \multirow[t]{3}{*}{$e_{4}$} & $A_{1}$ & $\begin{array}{l}(0.50|0.2,0.60| 0.3 \\
0.70 \mid 0.5)\end{array}$ & $(0.72|0.6,0.80| 0.2)$ & $(0.30|0.4,0.50| 0.6)$ & $\begin{array}{l}(0.65|0.5,0.70| 0.2 \\
0.83 \mid 0.3)\end{array}$ & $(0.60|0.5,0.70| 0.5)$ \\
\hline & $A_{2}$ & $(0.71|0.4,0.83| 0.4)$ & $\begin{array}{l}(0.65|0.5,0.70| 0.1 \\
0.83 \mid 0.4)\end{array}$ & $(0.77 \mid 1.0)$ & $(0.53|0.5,0.67| 0.5)$ & $(0.51|0.4,0.63| 0.6)$ \\
\hline & $A_{3}$ & $\begin{array}{l}(0.80|0.5,0.85| 0.3 \\
0.9 \mid 0.2)\end{array}$ & $\begin{array}{l}(0.35|0.2,0.44| 0.4 \\
0.50 \mid 0.4)\end{array}$ & $(0.56|0.2,0.66| 0.8)$ & $(0.50|0.4,0.65| 0.6)$ & $(0.62|0.3,0.75| 0.7)$ \\
\hline
\end{tabular}

for analysis are expressed by PHFE $h_{i j}^{s t}\left(\gamma_{i} \mid p_{i}\right)$. The decision matrix $D_{s}^{t}=\left(h_{i j}^{s t}\left(\gamma_{i} \mid p_{i}\right)\right)_{m \times n}$ is obtained. The results are shown in Tables 2, 3, 4.

Step 2: Because attribute $C_{1}$ and attribute $C_{5}$ belong to cost attribute, attribute $C_{2}$, attribute $C_{3}$, and attribute $C_{4}$ belong to benefit attribute. Therefore, the normalized decision matrices are shown in Tables 5, 6, 7 .

Step 3: Aggregate the normalized attribute value using Eq. (11), the result can be seen in Table 8 .

Step 4: According to Eqs. (12, 13, 14), the attribute weight in different states can be obtained as follows:

In $Z_{1}$ state, the attribute weights are $\omega_{z 1}=(0.322$, $0.059,0.187,0.075,0.358)^{\mathrm{T}}$;

In $Z_{2}$ state, the attribute weights are $\omega_{z 2}=(0.204$, $0.112,0.039,0.297,0.347)^{\mathrm{T}}$;

In $Z_{3}$ state, the attribute weights are $\omega_{z 3}=(0.394$, $0.192,0.045,0.066,0.303)^{\mathrm{T}}$.

Step 5: Calculate PHFHWD $\left(\mathrm{H}_{\mathrm{pi}}, \mathrm{H}_{\mathrm{p}+}\right)$ and PHFHWD $\left(\bar{H}_{p i}, \bar{H}_{p-}\right)$ measures using Eq. (10), where $\bar{H}_{p+}$ and $\bar{H}_{p-}$ are denoted as probabilistic hesitant fuzzy positive ideal solution (PHFPIS) and probabilistic hesitant fuzzy negative ideal solution (PHFNIS), respectively. Assume that the ordered weights are $w=(0.26,0.35,0.39)^{\mathrm{T}}$, according to the score function, the PHFPIS and PHFNIS in different states can be obtained as follows:

$$
\begin{aligned}
\bar{H}_{p+}^{Z_{1}}= & \{(0.30|0.36,0.33| 0.56,0.29 \mid 0.08), \\
& (0.68|0.21,0.70| 0.69,0.76 \mid 0.10), \\
& (0.79|0.23,0.78| 0.42,0.82 \mid 0.35), \\
& (0.78|0.46,0.77| 0.42,0.69 \mid 0.12), \\
& (0.29|0.13,0.28| 0.44,0.28 \mid 0.44)\} \\
\bar{H}_{p+}^{Z_{2}}= & \{(0.38|0.42,0.36| 0.47,0.47 \mid 0.31), \\
& (0.71|0.32,0.71| 0.61,0.74 \mid 0.07), \\
& (0.66|0.05,0.74| 0.25,0.78 \mid 0.70), \\
& (0.74|0.32,0.77| 0.48,0.72 \mid 0.20), \\
& (0.39|0.58,0.36| 0.17,0.21 \mid 0.25)\}
\end{aligned}
$$


Table 4 Evaluation values of alternative in state $Z_{3}$

\begin{tabular}{|c|c|c|c|c|c|c|}
\hline \multirow[t]{2}{*}{ DM } & \multirow[t]{2}{*}{ Alternative } & \multicolumn{5}{|l|}{ Attribute } \\
\hline & & $C_{1}$ & $C_{2}$ & $C_{3}$ & $C_{4}$ & $C_{5}$ \\
\hline \multirow[t]{3}{*}{$e_{1}$} & $A_{1}$ & $\begin{array}{l}(0.55|0.2,0.63| 0.6 \\
0.79 \mid 0.2)\end{array}$ & $(0.52|0.4,0.61| 0.6)$ & $(0.51|0.4,0.63| 0.6)$ & $(0.51|0.4,0.63| 0.6)$ & $\begin{array}{l}(0.71|0.4,0.83| 0.1, \\
0.95 \mid 0.5)\end{array}$ \\
\hline & $A_{2}$ & $(0.67|0.5,0.85| 0.5)$ & $\begin{array}{l}(0.40|0.3,0.55| 0.3 \\
0.69 \mid 0.4)\end{array}$ & $\begin{array}{l}(0.50|0.2,0.60| 0.3 \\
0.71 \mid 0.5)\end{array}$ & $(0.60|0.6,0.75| 0.2)$ & $(0.70|0.5,0.80| 0.5)$ \\
\hline & $A_{3}$ & $\begin{array}{l}(0.80|0.5,0.85| 0.3, \\
0.9 \mid 0.2)\end{array}$ & $\begin{array}{l}(0.65|0.5,0.70| 0.2 \\
0.83 \mid 0.3)\end{array}$ & $(0.51|0.4,0.63| 0.6)$ & $(0.50|0.4,0.65| 0.6)$ & $(0.62|0.3,0.75| 0.7)$ \\
\hline \multirow[t]{3}{*}{$e_{2}$} & $A_{1}$ & $(0.79 \mid 1.0)$ & $(0.30|0.4,0.50| 0.6)$ & $(0.58|0.3,0.79| 0.7)$ & $\begin{array}{l}(0.59|0.5,0.66| 0.3 \\
0.81 \mid 0.2)\end{array}$ & $\begin{array}{l}(0.87|0.3,0.67| 0.6 \\
0.93 \mid 0.2)\end{array}$ \\
\hline & $A_{2}$ & $(0.63|0.6,0.56| 0.4)$ & $(0.65 \mid 1.0)$ & $(0.89|0.6,0.92| 0.3)$ & $(0.79|0.3,0.68| 0.5)$ & $\begin{array}{l}(0.82|0.3,0.73| 0.6 \\
0.63 \mid 0.1)\end{array}$ \\
\hline & $A_{3}$ & $(0.43|0.3,0.66| 0.4)$ & $\begin{array}{l}(0.63|0.3,0.73| 0.4 \\
0.69 \mid 0.3)\end{array}$ & $(0.79|0.6,0.71| 0.4)$ & $(0.87|0.6,0.71| 0.4)$ & $(0.82|0.4,0.72| 0.6)$ \\
\hline \multirow[t]{3}{*}{$e_{3}$} & $A_{1}$ & $(0.88 \mid 1.0)$ & $(0.66 \mid 1.0)$ & $(0.87|0.7,0.71| 0.3)$ & $(0.69 \mid 0.5)$ & $(0.69|0.6,0.74| 0.4)$ \\
\hline & $A_{2}$ & $(0.71|0.4,0.89| 0.5)$ & $(0.89|0.6,0.92| 0.3)$ & $(0.76 \mid 0.8)$ & $(0.81|0.4,0.82| 0.3)$ & $(0.81 \mid 0.4)$ \\
\hline & $A_{3}$ & $(0.89|0.5,0.79| 0.3)$ & $(0.82 \mid 1.0)$ & $(0.7611 .0)$ & $\begin{array}{l}(0.86|0.6,0.79| 0.3 \\
0.57 \mid 0.1)\end{array}$ & $(0.80 \mid 1.0)$ \\
\hline \multirow[t]{3}{*}{$e_{4}$} & $A_{1}$ & $(0.73 \mid 1.0)$ & $(0.79|0.3,0.68| 0.5)$ & $\begin{array}{l}(0.67|0.4,0.83| 0.3 \\
0.96 \mid 0.3)\end{array}$ & $(0.80 \mid 1.0)$ & $(0.82|0.6,0.76| 0.4)$ \\
\hline & $A_{2}$ & $\begin{array}{l}(0.76|0.5,0.69| 0.2 \\
0.86 \mid 0.3)\end{array}$ & $(0.63|0.6,0.56| 0.4)$ & $(0.86|0.4,0.79| 0.5)$ & $(0.86 \mid 1.0)$ & $(0.71 \mid 0.8)$ \\
\hline & $A_{3}$ & $(0.69|0.4,0.59| 0.6)$ & $\begin{array}{l}(0.76|0.4,0.69| 0.5 \\
0.86 \mid 0.1)\end{array}$ & $\begin{array}{l}(0.57|0.3,0.76| 0.5 \\
0.88 \mid 0.2)\end{array}$ & $(0.66|0.5,0.73| 0.5)$ & $(0.62 \mid 1.0)$ \\
\hline
\end{tabular}

$\bar{H}_{p+}^{Z_{3}}=\{(0.32|0.50,0.36| 0.27,0.27 \mid 0.24)$,

$(0.73|0.55,0.74| 0.37,0.81 \mid 0.08)$,

$(0.79|0.23,0.78| 0.42,0.82 \mid 0.35)$,

$(0.78|0.32,0.76| 0.54,0.79 \mid 0.14)$,

$(0.29|0.13,0.28| 0.44,0.28 \mid 0.44)\}$

$\bar{H}_{p-}^{Z_{1}}=\{(0.25|0.45,0.28| 0.33,0.27 \mid 0.22)$,

$(0.66|0.21,0.64| 0.47,0.66 \mid 0.32)$,

$(0.71|0.09,0.69| 0.74,0.77 \mid 0.16)$,

$(0.66|0.22,0.70| 0.56,0.75 \mid 0.22)$,

$(0.22|0.27,0.24| 0.55,0.24 \mid 0.18)\}$

$\bar{H}_{p-}^{Z_{2}}=\{(0.34|0.33,0.31| 0.33,0.26 \mid 0.33)$,

$(0.59|0.83,0.69| 0.05,0.80 \mid 0.13)$,

$(0.66|0.11,0.71| 0.59,0.73 \mid 0.30)$,

$(0.57|0.47,0.63| 0.47,0.71 \mid 0.07)$,

$(0.25|0.29,0.30| 0.57,0.18 \mid 0.14)\}$

$\bar{H}_{p-}^{\mathrm{Z}_{3}}=\{(0.27|0.20,0.25| 0.60,0.20 \mid 0.20)$,

$(0.61|0.12,0.62| 0.44,0.62 \mid 0.44)$,

$(0.68|0.24,0.74| 0.60,0.76 \mid 0.16)$,

$(0.67|0.40,0.70| 0.36,0.74 \mid 0.24)$,

$(0.23|0.53,0.25| 0.27,0.16 \mid 0.20)\}$.
PHFHWD is calculated under different states and different $\lambda$, and the results can be seen in Table 9 .

Step 6: The results from step 5 are put into Eq. (5), yielding the dominance degree $\phi_{j}\left(A_{i}, A_{+}\right)$and $\phi_{j}\left(A_{i}, A_{-}\right)$ of alternative $A_{i}$ over PHFPIS $A_{+}$and PHFNIS $A_{-}$, respectively. Table 10 shows the results.

Step 7: Calculate comprehensive dominance degree $\phi\left(A_{i}, A_{q}\right)$ of alternative $A_{i}$ over alternative $A_{q}$ for attribute $C_{j}$ using Eq. (6). The results can be seen in Table 11.

Step 8: Find the overall dominance value $\Phi\left(A_{i}\right)$ of alternative $A_{i}$, and rank the alternatives using $\Phi\left(A_{i}\right)$. The larger $\Phi\left(A_{i}\right)$ is, the better is alternative $A_{i}$ as an emergency response (Table 12).

Step 9: From Table 12, the ranking obtained by the proposed method is insensitive to $\lambda$. The optimal emergency response changes with state $Z_{i}$, which also explains the need to consider the EDM method from a dynamic perspective. The best emergency response for each state is now provided as a tuple: $\left(\left(Z_{1}, A_{2}\right),\left(Z_{2}, A_{3}\right),\left(Z_{3}, A_{3}\right)\right)$.

Next, Fig. 4 shows the effect of a change in the parameter $\lambda$ on the overall dominance value. Notably, as $\lambda$ changes for each $Z_{i}$, and altering the overall dominance 
Table 5 Normalized decision matrix in state $Z_{1}$

\begin{tabular}{|c|c|c|c|c|c|c|}
\hline \multirow[t]{2}{*}{ DM } & \multirow[t]{2}{*}{ Alternative } & \multicolumn{5}{|l|}{ Attribute } \\
\hline & & $C_{1}$ & $C_{2}$ & $C_{3}$ & $C_{4}$ & $C_{5}$ \\
\hline \multirow[t]{3}{*}{$e_{1}$} & $A_{1}$ & $(0.16 \mid 1.0)$ & $(0.66 \mid 1.0)$ & $(0.65|0.4,0.86| 0.2)$ & $(0.69 \mid 0.5)$ & $(0.31|0.4,0.21| 0.4)$ \\
\hline & $A_{2}$ & $(0.14|0.4,0.21| 0.5)$ & $(0.76|0.4,0.79| 0.5)$ & $(0.76 \mid 0.4)$ & $(0.81|0.4,0.82| 0.3)$ & $(0.19 \mid 0.4)$ \\
\hline & $A_{3}$ & $(0.11|0.5,0.21| 0.3)$ & $(0.82 \mid 1.0)$ & $(0.76 \mid 1.0)$ & $\begin{array}{l}(0.89|0.5,0.79| 0.3 \\
0.67 \mid 0.2)\end{array}$ & $(0.20 \mid 1.0)$ \\
\hline \multirow[t]{3}{*}{$e_{2}$} & $A_{1}$ & $(0.27 \mid 1.0)$ & $(0.82|0.4,0.72| 0.6)$ & $\begin{array}{l}(0.65|0.4,0.86| 0.4 \\
0.96 \mid 0.2)\end{array}$ & $(0.80 \mid 1.0)$ & $(0.18|0.6,0.24| 0.4)$ \\
\hline & $A_{2}$ & $\begin{array}{l}(0.24|0.4,0.31| 0.5 \\
0.14 \mid 0.1)\end{array}$ & $(0.76|0.4,0.69| 0.5)$ & $(0.86|0.4,0.79| 0.5)$ & $(0.76 \mid 1.0)$ & $(0.19 \mid 0.4)$ \\
\hline & $A_{3}$ & $(0.31|0.4,0.41| 0.6)$ & $\begin{array}{l}(0.76|0.4,0.69| 0.5 \\
0.86 \mid 0.1)\end{array}$ & $\begin{array}{l}(0.69|0.3,0.76| 0.6 \\
0.88 \mid 0.2)\end{array}$ & $(0.66|0.5,0.73| 0.5)$ & $(0.38 \mid 1.0)$ \\
\hline \multirow[t]{3}{*}{$e_{3}$} & $A_{1}$ & $(0.5111 .0)$ & $(0.52|0.4,0.62| 0.6)$ & $(0.78|0.6,0.89| 0.4)$ & $\begin{array}{l}(0.69|0.3,0.76| 0.5 \\
0.88 \mid 0.2)\end{array}$ & $\begin{array}{l}(0.13|0.3,0.33| 0.6 \\
0.07 \mid 0.2)\end{array}$ \\
\hline & $A_{2}$ & $(0.31|0.6,0.41| 0.4)$ & $(0.65 \mid 1.0)$ & $(0.89|0.6,0.92| 0.3)$ & $(0.79|0.3,0.68| 0.5)$ & $\begin{array}{l}(0.18|0.3,0.27| 0.6 \\
0.37 \mid 0.2)\end{array}$ \\
\hline & $A_{3}$ & $(0.37|0.3,0.34| 0.4)$ & $\begin{array}{l}(0.63|0.3,0.73| 0.4 \\
0.69 \mid 0.3)\end{array}$ & $(0.79|0.6,0.71| 0.4)$ & $(0.87|0.7,0.71| 0.3)$ & $(0.18|0.4,0.28| 0.6)$ \\
\hline \multirow[t]{3}{*}{$e_{4}$} & $A_{1}$ & $\begin{array}{l}(0.37|0.2,0.27| 0.6 \\
0.11 \mid 0.2)\end{array}$ & $(0.55|0.6,0.61| 0.4)$ & $(0.60|0.8,0.70| 0.2)$ & $(0.33|0.4,0.45| 0.6)$ & $\begin{array}{l}(0.37|0.3,0.27| 0.3, \\
0.11 \mid 0.4)\end{array}$ \\
\hline & $A_{2}$ & $(0.47|0.5,0.35| 0.5)$ & $\begin{array}{l}(0.40|0.3,0.55| 0.3 \\
0.69 \mid 0.4)\end{array}$ & $\begin{array}{l}(0.50|0.2,0.60| 0.3 \\
0.71 \mid 0.5)\end{array}$ & $(0.60|0.6,0.75| 0.2)$ & $(0.30|0.5,0.20| 0.5)$ \\
\hline & $A_{3}$ & $\begin{array}{l}(0.20|0.5,0.15| 0.3, \\
0.1 \mid 0.2)\end{array}$ & $\begin{array}{l}(0.35|0.2,0.44| 0.4 \\
0.50 \mid 0.4)\end{array}$ & $(0.56|0.2,0.66| 0.8)$ & $(0.50|0.4,0.65| 0.6)$ & $(0.38|0.3,0.25| 0.7)$ \\
\hline
\end{tabular}

value of the alternatives, the ranking outcomes remain unchanged.

\subsection{Comparative Analysis}

To highlight the effectiveness and practicability of the proposed method, we perform comparative analysis for the proposed method from two aspects:

(1) The method proposed in this paper is compared with the probabilistic hesitant fuzzy distance measure proposed by Gao et al. [29], which ignored the psychological behavior of the decision-makers.

(2) The method proposed in this paper is compared with the TODIM analysis approach under a hesitant fuzzy environment [31], which considered the psychological behavior of decision-makers but ignored the occurring probabilities of the changes of external environment.

\subsubsection{Comparison with the Probabilistic Hesitant Fuzzy Distance Measure}

Tables 13 and 14 show the comparison results of the ranking with the probabilistic hesitant fuzzy distance measure [29].

Tables 13 and 14 show that both methods yield different results for the same state and $\lambda$. The results obtained from the proposed method are more stable for different values of $\lambda$ than these obtained from [29]. The decision outcomes are different under the two methods for the same fuzzy decision-making environment because some information was lost in [29]. This suggests that DM's psychological behavior can influence the decisions made. Hence, embedding the psychological behavior of the DMs can pan out a more realistic selection outcome.

\subsubsection{Comparison with the TODIM Analysis Approach Under a Hesitant Fuzzy Environment}

Similarly, we compare our results against the TODIM analysis method under a hesitant fuzzy environment [31], which is used to handle the same emergency event employed in this paper, but without considering the 
Table 6 Normalized decision matrix in state $Z_{2}$

\begin{tabular}{|c|c|c|c|c|c|c|}
\hline \multirow[t]{2}{*}{ DM } & \multirow[t]{2}{*}{ Alternative } & \multicolumn{5}{|l|}{ Attribute } \\
\hline & & $C_{1}$ & $C_{2}$ & $C_{3}$ & $C_{4}$ & $C_{5}$ \\
\hline \multirow[t]{3}{*}{$e_{1}$} & $A_{1}$ & $\begin{array}{l}(0.20|0.5,0.15| 0.3 \\
0.11 \mid 0.2)\end{array}$ & $(0.78|0.6,0.82| 0.2)$ & $\begin{array}{l}(0.68|0.4,0.75| 0.3 \\
0.89 \mid 0.3)\end{array}$ & $(0.50|0.5,0.67| 0.5)$ & $(0.27|0.4,0.13| 0.3)$ \\
\hline & $A_{2}$ & $(0.32|0.5,0.28| 0.5)$ & $(0.53|0.5,0.67| 0.5)$ & $(0.76|0.3,0.87| 0.7)$ & $\begin{array}{l}(0.50|0.3,0.60| 0.3 \\
0.70 \mid 0.4)\end{array}$ & $\begin{array}{l}(0.30|0.2,0.20| 0.2 \\
0.10 \mid 0.4)\end{array}$ \\
\hline & $A_{3}$ & $(0.24|0.4,0.21| 0.5)$ & $\begin{array}{l}(0.69|0.3,0.76| 0.6 \\
0.88 \mid 0.2)\end{array}$ & $(0.65 \mid 1.0)$ & $(0.80 \mid 1.0)$ & $(0.18|0.6,0.24| 0.4)$ \\
\hline \multirow[t]{3}{*}{$e_{2}$} & $A_{1}$ & $\begin{array}{l}(0.24|0.4,0.31| 0.5 \\
0.24 \mid 0.1)\end{array}$ & $(0.76|0.4,0.69| 0.5)$ & $(0.86|0.4,0.79| 0.5)$ & $(0.76 \mid 1.0)$ & $(0.19 \mid 0.4)$ \\
\hline & $A_{2}$ & $(0.47|0.5,0.23| 0.5)$ & $\begin{array}{l}(0.72|0.7,0.80| 0.2 \\
0.90 \mid 0.1)\end{array}$ & $\begin{array}{l}(0.53|0.2,0.60| 0.3 \\
0.74 \mid 0.5)\end{array}$ & $(0.63|0.6,0.71| 0.2)$ & $\begin{array}{l}(0.45|0.7,0.40| 0.2, \\
0.16 \mid 0.1)\end{array}$ \\
\hline & $A_{3}$ & $(0.49|0.4,0.37| 0.6)$ & $(0.63|0.7,0.70| 0.3)$ & $\begin{array}{l}(0.60|0.3,0.70| 0.4 \\
0.84 \mid 0.3)\end{array}$ & $(0.63|0.5,0.70| 0.5)$ & $\begin{array}{l}(0.50|0.7,0.40| 0.2, \\
0.16 \mid 0.1)\end{array}$ \\
\hline \multirow[t]{3}{*}{$e_{3}$} & $A_{1}$ & $(0.51 \mid 1.0)$ & $(0.52|0.4,0.62| 0.6)$ & $(0.78|0.6,0.89| 0.4)$ & $\begin{array}{l}(0.69|0.3,0.76| 0.5 \\
0.88 \mid 0.2)\end{array}$ & $\begin{array}{l}(0.13|0.3,0.33| 0.6 \\
0.07 \mid 0.2)\end{array}$ \\
\hline & $A_{2}$ & $(0.47|0.5,0.35| 0.5)$ & $\begin{array}{l}(0.40|0.3,0.55| 0.3 \\
0.69 \mid 0.4)\end{array}$ & $\begin{array}{l}(0.50|0.2,0.60| 0.3 \\
0.71 \mid 0.5)\end{array}$ & $(0.60|0.6,0.75| 0.2)$ & $(0.30|0.5,0.20| 0.5)$ \\
\hline & $A_{3}$ & $(0.37|0.3,0.34| 0.4)$ & $\begin{array}{l}(0.63|0.3,0.73| 0.4 \\
0.69 \mid 0.3)\end{array}$ & $(0.79|0.6,0.71| 0.4)$ & $(0.87|0.7,0.71| 0.3)$ & $(0.18|0.4,0.28| 0.6)$ \\
\hline \multirow[t]{3}{*}{$e_{4}$} & $A_{1}$ & $\begin{array}{l}(0.50|0.2,0.40| 0.3 \\
0.30 \mid 0.5)\end{array}$ & $(0.72|0.6,0.80| 0.2)$ & $(0.30|0.4,0.50| 0.6)$ & $\begin{array}{l}(0.65|0.5,0.70| 0.2 \\
0.83 \mid 0.3)\end{array}$ & $(0.40|0.5,0.30| 0.5)$ \\
\hline & $A_{2}$ & $(0.29|0.4,0.17| 0.4)$ & $\begin{array}{l}(0.65|0.5,0.70| 0.1 \\
0.83 \mid 0.4)\end{array}$ & $(0.77 \mid 1.0)$ & $(0.53|0.5,0.67| 0.5)$ & $(0.49|0.4,0.37| 0.6)$ \\
\hline & $A_{3}$ & $\begin{array}{l}(0.20|0.5,0.15| 0.3 \\
0.10 \mid 0.2)\end{array}$ & $\begin{array}{l}(0.35|0.2,0.44| 0.4 \\
0.50 \mid 0.4)\end{array}$ & $(0.56|0.2,0.66| 0.8)$ & $(0.50|0.4,0.65| 0.6)$ & $(0.38|0.3,0.25| 0.7)$ \\
\hline
\end{tabular}

possibility of the alteration of the external environment. To do this, we remove the probabilities, i.e., the probabilistic hesitant fuzzy numbers in Tables 2, 3, and 4 are now hesitant fuzzy numbers. Applying the TODIM approach under a hesitant fuzzy environment in [31] yields the required ranking results (see Tables 15,16 ).

Tables 15 and 16 show that by applying [31], the best choice is state-dependent for the same $\lambda$ and $\lambda$ is dependent for the same state. Hence, there would be difficulty in reaching a consensus-based best emergency response. The former is easy to be understood since the best choice for each state need not necessarily be the same. $\lambda$ is not a factor that affects the DM's psychological behavior, the latter case would suggest that we need to factor the DM's psychology. The proposed method presents more robust decision responses, as shown in state $Z_{1}$, where the optimal response under a hesitant fuzzy environment is such that $A_{3} \rightarrow A_{2}$ when $\lambda$ shifts. The results under a probabilistic hesitant fuzzy environment hold at $A_{2} \rightarrow A_{2}$, when $\lambda$ shifts. The reason is that the occurrence probabilities of the change in the emergency are downplayed.

\subsection{Discussion}

From the comparisons conducted, some advantages of the proposed method are summarized as:

(1) Our method treats not only the importance of the attribute, but also the importance of the position of the attribute. As such, we can improve the TODIM method through our approach to take into account the psychological behavior of the DMs by appropriately recognizing such positions.

(2) Compared to Zhang et al. [31], our approach acknowledges the rapidity of the external environment and weights it accordingly by assigning a 
Table 7 Normalized decision matrix in state $Z_{3}$

\begin{tabular}{|c|c|c|c|c|c|c|}
\hline \multirow[t]{2}{*}{ DM } & \multirow[t]{2}{*}{ Alternative } & \multicolumn{5}{|l|}{ Attribute } \\
\hline & & $C_{1}$ & $C_{2}$ & $C_{3}$ & $C_{4}$ & $C_{5}$ \\
\hline \multirow[t]{3}{*}{$e_{1}$} & $A_{1}$ & $\begin{array}{l}(0.45|0.2,0.37| 0.6 \\
0.21 \mid 0.2)\end{array}$ & $(0.52|0.4,0.61| 0.6)$ & $(0.51|0.4,0.63| 0.6)$ & $(0.51|0.4,0.63| 0.6)$ & $\begin{array}{l}(0.29|0.4,0.17| 0.1 \\
0.05 \mid 0.5)\end{array}$ \\
\hline & $A_{2}$ & $(0.33|0.5,0.15| 0.5)$ & $\begin{array}{l}(0.40|0.3,0.55| 0.3 \\
0.69 \mid 0.4)\end{array}$ & $\begin{array}{l}(0.50|0.2,0.60| 0.3 \\
0.71 \mid 0.5)\end{array}$ & $(0.60|0.6,0.75| 0.2)$ & $(0.30|0.5,0.20| 0.5)$ \\
\hline & $A_{3}$ & $\begin{array}{l}(0.20|0.5,0.15| 0.3 \\
0.10 \mid 0.2)\end{array}$ & $\begin{array}{l}(0.65|0.5,0.70| 0.2 \\
0.83 \mid 0.3)\end{array}$ & $(0.51|0.4,0.63| 0.6)$ & $(0.50|0.4,0.65| 0.6)$ & $(0.38|0.3,0.25| 0.7)$ \\
\hline \multirow[t]{3}{*}{$e_{2}$} & $A_{1}$ & $(0.2111 .0)$ & $(0.30|0.4,0.50| 0.6)$ & $(0.58|0.3,0.79| 0.7)$ & $\begin{array}{l}(0.59|0.5,0.66| 0.3 \\
0.81 \mid 0.2)\end{array}$ & $\begin{array}{l}(0.13|0.3,0.33| 0.6 \\
0.07 \mid 0.2)\end{array}$ \\
\hline & $A_{2}$ & $(0.37|0.6,0.44| 0.4)$ & $(0.65 \mid 1.0)$ & $(0.89|0.6,0.92| 0.3)$ & $(0.79|0.3,0.68| 0.5)$ & $\begin{array}{l}(0.18|0.3,0.27| 0.6 \\
0.37 \mid 0.1)\end{array}$ \\
\hline & $A_{3}$ & $(0.57|0.3,0.34| 0.4)$ & $\begin{array}{l}(0.63|0.3,0.73| 0.4 \\
0.69 \mid 0.3)\end{array}$ & $(0.79|0.6,0.71| 0.4)$ & $(0.87|0.6,0.71| 0.4)$ & $(0.18|0.4,0.28| 0.6)$ \\
\hline \multirow[t]{3}{*}{$e_{3}$} & $A_{1}$ & $(0.12 \mid 1.0)$ & $(0.66 \mid 1.0)$ & $(0.87 \mid 0.7,0.7110 .3)$ & $(0.69 \mid 0.5)$ & $(0.31|0.6,0.26| 0.4)$ \\
\hline & $A_{2}$ & $(0.29|0.4,0.11| 0.5)$ & $(0.89|0.6,0.92| 0.3)$ & $(0.7610 .8)$ & $(0.81|0.4,0.82| 0.3)$ & $(0.19 \mid 0.4)$ \\
\hline & $A_{3}$ & $(0.11 \mid 0.5,0.2110 .3)$ & $(0.82 \mid 1.0)$ & $(0.76 \mid 1.0)$ & $\begin{array}{l}(0.86|0.6,0.79| 0.3 \\
0.57 \mid 0.1)\end{array}$ & $(0.20 \mid 1.0)$ \\
\hline \multirow[t]{3}{*}{$e_{4}$} & $A_{1}$ & $(0.27 \mid 1.0)$ & $(0.79|0.3,0.68| 0.5)$ & $\begin{array}{l}(0.67|0.4,0.83| 0.3 \\
0.96 \mid 0.3)\end{array}$ & $(0.80 \mid 1.0)$ & $(0.18|0.6,0.24| 0.4)$ \\
\hline & $A_{2}$ & $\begin{array}{l}(0.24|0.5,0.31| 0.2 \\
0.14 \mid 0.3)\end{array}$ & $(0.63|0.6,0.56| 0.4)$ & $(0.86|0.4,0.79| 0.5)$ & $(0.86 \mid 1.0)$ & $(0.29 \mid 0.8)$ \\
\hline & $A_{3}$ & $(0.31|0.4,0.41| 0.6)$ & $\begin{array}{l}(0.76|0.4,0.69| 0.5 \\
0.86 \mid 0.1)\end{array}$ & $\begin{array}{l}(0.57|0.3,0.76| 0.5 \\
0.88 \mid 0.2)\end{array}$ & $(0.66|0.5,0.73| 0.5)$ & $(0.38 \mid 1.0)$ \\
\hline
\end{tabular}

position of importance to the attribute weights to reflect the preference of the DMs, thus avoiding the loss of pertinent information.

(3) The proposed method recognizes both the dynamism of emergency decision-making situations and the mental pressures faced by the DMs, akin to an actual large-scale emergency decision-making environment. This method serves better in practical emergency response situations. The proposal provides theoretical support for practical application and at the same time provides a reference for the policy formulation of emergency departments.

However, the method proposed in this paper has a limitation, that is, the mathematical model of probabilistic hesitant fuzzy numbers cannot be universally applied to other types of fuzzy decision-making problems.

\section{Conclusion and Future Works}

With uncertainty in the external environment, the vagueness and complexity of emergencies may exert more challenges for decision-makers. The probabilistic hesitant fuzzy set is the latest extension of the hesitant fuzzy set, which is intended to cope with changes in the external environment. We extend this approach by considering simultaneously the changes in the importance of the criteria and importance of the position of that criteria, particularly where it concerns the psychology of the decision-makers and the dynamic external environment. Specifically, we introduce the concept of the hybrid weighted distance of the probabilistic hesitant fuzzy set to extend the TODIM method to increase the flexibility and richness of dealing with dynamic EDM problems. In short, this paper dynamically adjusts the emergency response according to 
Table 8 Group decision-making matrix for the three states

\begin{tabular}{|c|c|c|c|c|c|c|}
\hline \multirow[t]{2}{*}{ State } & \multirow[t]{2}{*}{ Alternative } & \multicolumn{5}{|l|}{ Attribute } \\
\hline & & $C_{1}$ & $C_{2}$ & $C_{3}$ & $C_{4}$ & $C_{5}$ \\
\hline \multirow[t]{3}{*}{$Z_{1}$} & $A_{1}$ & $\begin{array}{l}(0.34|0.20,0.32| 0.60 \\
0.28 \mid 0.20)\end{array}$ & $\begin{array}{l}(0.66|0.21,0.64| 0.47 \\
0.66 \mid 0.32)\end{array}$ & $\begin{array}{l}(0.68|0.49,0.74| 0.49, \\
0.88 \mid 0.02)\end{array}$ & $\begin{array}{l}(0.66|0.22,0.70| 0.56 \\
0.75 \mid 0.22)\end{array}$ & $\begin{array}{l}(0.25|0.34,0.29| 0.46 \\
0.16 \mid 0.20)\end{array}$ \\
\hline & $A_{2}$ & $\begin{array}{l}(0.30|0.36,0.33| 0.56 \\
0.29 \mid 0.08)\end{array}$ & $\begin{array}{l}(0.67|0.22,0.68| 0.34 \\
0.71 \mid 0.45)\end{array}$ & $\begin{array}{l}(0.79|0.23,0.78| 0.42 \\
0.82 \mid 0.35)\end{array}$ & $\begin{array}{l}(0.75|0.32,0.72| 0.54 \\
0.76 \mid 0.14)\end{array}$ & $\begin{array}{l}(0.22|0.27,0.24| 0.55 \\
0.24 \mid 0.18)\end{array}$ \\
\hline & $A_{3}$ & $\begin{array}{l}(0.25|0.45,0.28| 0.33 \\
0.27 \mid 0.22)\end{array}$ & $\begin{array}{l}(0.68|0.21,0.70| 0.69 \\
0.76 \mid 0.10)\end{array}$ & $\begin{array}{l}(0.71|0.09,0.69| 0.74 \\
0.77 \mid 0.16)\end{array}$ & $\begin{array}{l}(0.78|0.46,0.77| 0.42, \\
0.69 \mid 0.12)\end{array}$ & $\begin{array}{l}(0.29|0.12,0.28| 0.44, \\
0.28 \mid 0.44)\end{array}$ \\
\hline \multirow[t]{3}{*}{$Z_{2}$} & $A_{1}$ & $\begin{array}{l}(0.38|0.42,0.36| 0.47 \\
0.31 \mid 0.11)\end{array}$ & $\begin{array}{l}(0.71|0.32,0.71| 0.61 \\
0.74 \mid 0.07)\end{array}$ & $\begin{array}{l}(0.71|0.30,0.72| 0.42 \\
0.81 \mid 0.28)\end{array}$ & $\begin{array}{l}(0.66|0.48,0.73| 0.32 \\
0.80 \mid 0.19)\end{array}$ & $\begin{array}{l}(0.25|0.29,0.30| 0.57 \\
0.18 \mid 0.14)\end{array}$ \\
\hline & $A_{2}$ & $\begin{array}{l}(0.39|0.33,0.39| 0.33 \\
0.26 \mid 0.33)\end{array}$ & $\begin{array}{l}(0.59|0.83,0.69| 0.05 \\
0.80 \mid 0.13)\end{array}$ & $\begin{array}{l}(0.66|0.05,0.74| 0.25 \\
0.78 \mid 0.70)\end{array}$ & $\begin{array}{l}(0.57|0.47,0.63| 0.47 \\
0.71 \mid 0.06)\end{array}$ & $\begin{array}{l}(0.39|0.58,0.36| 0.17 \\
0.21 \mid 0.25)\end{array}$ \\
\hline & $A_{3}$ & $\begin{array}{l}(0.34|0.33,0.31| 0.33 \\
0.26 \mid 0.33)\end{array}$ & $\begin{array}{l}(0.59|0.14,0.66| 0.77 \\
0.73 \mid 0.08)\end{array}$ & $\begin{array}{l}(0.66|0.11,0.71| 0.59 \\
0.73 \mid 0.30)\end{array}$ & $\begin{array}{l}(0.74|0.32,0.77| 0.48 \\
0.72 \mid 0.20)\end{array}$ & $\begin{array}{l}(0.32|0.56,0.27| 0.25 \\
0.23 \mid 0.19)\end{array}$ \\
\hline \multirow[t]{3}{*}{$Z_{3}$} & $A_{1}$ & $\begin{array}{l}(0.27|0.20,0.25| 0.60 \\
0.20 \mid 0.20)\end{array}$ & $\begin{array}{l}(0.61|0.12,0.62| 0.44 \\
0.62 \mid 0.44)\end{array}$ & $\begin{array}{l}(0.69|0.21,0.80| 0.55 \\
0.83 \mid 0.24)\end{array}$ & $\begin{array}{l}(0.67|0.40,0.70| 0.36 \\
0.74 \mid 0.24)\end{array}$ & $\begin{array}{l}(0.23|0.53,0.25| 0.27 \\
0.16 \mid 0.20)\end{array}$ \\
\hline & $A_{2}$ & $\begin{array}{l}(0.31|0.53,0.33| 0.21, \\
0.22 \mid 0.26)\end{array}$ & $\begin{array}{l}(0.70|0.41,0.72| 0.41 \\
0.75 \mid 0.18)\end{array}$ & $\begin{array}{l}(0.79|0.23,0.78| 0.42, \\
0.82 \mid 0.35)\end{array}$ & $\begin{array}{l}(0.78|0.32,0.76| 0.54 \\
0.79 \mid 0.14)\end{array}$ & $\begin{array}{l}(0.24|0.30,0.26| 0.60 \\
0.27 \mid 0.10)\end{array}$ \\
\hline & $A_{3}$ & $\begin{array}{l}(0.32|0.50,0.36| 0.27 \\
0.27 \mid 0.24)\end{array}$ & $\begin{array}{l}(0.73|0.55,0.74| 0.37 \\
0.81 \mid 0.08)\end{array}$ & $\begin{array}{l}(0.68|0.24,0.74| 0.60 \\
0.76 \mid 0.16)\end{array}$ & $\begin{array}{l}(0.78|0.52,0.77| 0.39 \\
0.67 \mid 0.09)\end{array}$ & $\begin{array}{l}(0.29|0.12,0.28| 0.44 \\
0.28 \mid 0.44)\end{array}$ \\
\hline
\end{tabular}

Table 9 PHFHWD measure for $Z_{i}$ and different $\lambda$

\begin{tabular}{|c|c|c|c|c|c|c|c|c|c|c|c|c|}
\hline \multirow[t]{2}{*}{ State } & \multirow[t]{2}{*}{$\lambda$} & & \multicolumn{5}{|c|}{$\operatorname{PHFHWD}\left(\mathrm{H}_{\mathrm{p}_{\mathrm{i}}}, \mathrm{H}_{\mathrm{p}+}\right)$} & \multicolumn{5}{|c|}{$\operatorname{PHFHWD}\left(\mathrm{H}_{\mathrm{p}_{\mathrm{i}}}, \mathrm{H}_{\mathrm{p}-}\right)$} \\
\hline & & & $\tilde{C}_{1}$ & $\tilde{C}_{2}$ & $\tilde{C}_{3}$ & $\tilde{C}_{4}$ & $\tilde{C}_{5}$ & $\tilde{C}_{1}$ & $\tilde{C}_{2}$ & $\tilde{C}_{3}$ & $\tilde{C}_{4}$ & $\tilde{C}_{5}$ \\
\hline \multirow[t]{6}{*}{$Z_{t 1}$} & \multirow[t]{3}{*}{$\lambda=1$} & $A_{1}$ & 0.002 & 0.010 & 0.002 & 0.014 & 0.004 & 0.032 & 0.019 & 0.005 & 0.000 & 0.000 \\
\hline & & $A_{2}$ & 0.000 & 0.000 & 0.001 & 0.001 & 0.003 & 0.027 & 0.018 & 0.001 & 0.000 & 0.000 \\
\hline & & $A_{3}$ & 0.000 & 0.000 & 0.000 & 0.011 & 0.004 & 0.024 & 0.003 & 0.001 & 0.000 & 0.000 \\
\hline & \multirow[t]{3}{*}{$\lambda=2$} & $A_{1}$ & 0.042 & 0.011 & 0.072 & 0.014 & 0.041 & 0.124 & 0.067 & 0.019 & 0.000 & 0.000 \\
\hline & & $A_{2}$ & 0.000 & 0.000 & 0.009 & 0.045 & 0.008 & 0.107 & 0.064 & 0.006 & 0.028 & 0.018 \\
\hline & & $A_{3}$ & 0.000 & 0.000 & 0.000 & 0.049 & 0.041 & 0.022 & 0.011 & 0.052 & 0.000 & 0.000 \\
\hline \multirow[t]{6}{*}{$Z_{t 2}$} & \multirow[t]{3}{*}{$\lambda=1$} & $A_{1}$ & 0.000 & 0.000 & 0.001 & 0.015 & 0.009 & 0.016 & 0.024 & 0.007 & 0.000 & 0.000 \\
\hline & & $A_{2}$ & 0.000 & 0.000 & 0.005 & 0.014 & 0.002 & 0.063 & 0.001 & 0.002 & 0.000 & 0.000 \\
\hline & & $A_{3}$ & 0.000 & 0.010 & 0.001 & 0.002 & 0.002 & 0.020 & 0.035 & 0.018 & 0.000 & 0.000 \\
\hline & \multirow[t]{3}{*}{$\lambda=2$} & $A_{1}$ & 0.000 & 0.000 & 0.011 & 0.071 & 0.068 & 0.078 & 0.089 & 0.035 & 0.004 & 0.000 \\
\hline & & $A_{2}$ & 0.000 & 0.000 & 0.025 & 0.064 & 0.030 & 0.180 & 0.012 & 0.010 & 0.000 & 0.000 \\
\hline & & $A_{3}$ & 0.000 & 0.033 & 0.035 & 0.017 & 0.005 & 0.102 & 0.119 & 0.074 & 0.000 & 0.000 \\
\hline \multirow[t]{6}{*}{$Z_{t 3}$} & \multirow[t]{3}{*}{$\lambda=1$} & $A_{1}$ & 0.001 & 0.001 & 0.021 & 0.021 & 0.005 & 0.000 & 0.000 & 0.000 & 0.000 & 0.000 \\
\hline & & $A_{2}$ & 0.000 & 0.000 & 0.006 & 0.006 & 0.004 & 0.056 & 0.017 & 0.013 & 0.001 & 0.000 \\
\hline & & $A_{3}$ & 0.000 & 0.000 & 0.000 & 0.000 & 0.000 & 0.034 & 0.035 & 0.021 & 0.001 & 0.000 \\
\hline & \multirow[t]{3}{*}{$\lambda=2$} & $A_{1}$ & 0.007 & 0.010 & 0.101 & 0.075 & 0.050 & 0.003 & 0.000 & 0.000 & 0.000 & 0.000 \\
\hline & & $A_{2}$ & 0.000 & 0.000 & 0.020 & 0.034 & 0.031 & 0.092 & 0.128 & 0.055 & 0.005 & 0.005 \\
\hline & & $A_{3}$ & 0.000 & 0.000 & 0.000 & 0.005 & 0.006 & 0.133 & 0.097 & 0.101 & 0.010 & 0.000 \\
\hline
\end{tabular}


Table 10 Dominance degree for $Z_{i}$ and different $\lambda$

\begin{tabular}{|c|c|c|c|c|c|c|c|c|c|c|c|c|}
\hline \multirow[t]{2}{*}{ State } & \multirow[t]{2}{*}{$\lambda$} & \multirow[t]{2}{*}{ Alternative } & \multicolumn{5}{|c|}{$\sqrt{\omega_{j r}\left(d_{i j}-d_{q j}\right) / \sum_{j=1}^{m} \omega_{j r}}$} & \multicolumn{5}{|c|}{$-\frac{1}{\theta} \sqrt{\sum_{j=1}^{m} \omega_{j r} \times\left(d_{q j}-d_{i j}\right) / \omega_{j r}}$} \\
\hline & & & $\tilde{C}_{1}$ & $\tilde{C}_{2}$ & $\tilde{C_{3}}$ & $\tilde{C}_{4}$ & $\tilde{C}_{5}$ & $\tilde{C}_{1}$ & $\tilde{C}_{2}$ & $\tilde{C}_{3}$ & $\tilde{C}_{4}$ & $\tilde{C}_{5}$ \\
\hline \multirow[t]{6}{*}{$Z_{1}$} & \multirow[t]{3}{*}{$\lambda=1$} & $A_{1}$ & 0.105 & 0.069 & 0.032 & 0.000 & 0.000 & -0.073 & -0.237 & -0.133 & -0.473 & -0.745 \\
\hline & & $A_{2}$ & 0.098 & 0.067 & 0.014 & 0.009 & 0.000 & 0.000 & 0.000 & -0.100 & -0.141 & -0.700 \\
\hline & & $A_{3}$ & 0.093 & 0.025 & 0.015 & 0.000 & 0.000 & 0.000 & 0.000 & 0.000 & -0.410 & -0.741 \\
\hline & \multirow[t]{3}{*}{$\lambda=2$} & $A_{1}$ & 0.208 & 0.130 & 0.062 & 0.000 & 0.000 & -0.346 & -0.209 & -0.598 & -0.310 & -0.906 \\
\hline & & $A_{2}$ & 0.194 & 0.126 & 0.035 & 0.065 & 0.030 & 0.000 & 0.000 & -0.217 & -0.549 & -0.396 \\
\hline & & $A_{3}$ & 0.088 & 0.052 & 0.102 & 0.000 & 0.000 & 0.000 & 0.000 & 0.000 & -0.573 & -0.901 \\
\hline \multirow[t]{6}{*}{$Z_{2}$} & \multirow[t]{3}{*}{$\lambda=1$} & $A_{1}$ & 0.074 & 0.078 & 0.037 & 0.007 & 0.000 & 0.000 & 0.000 & -0.091 & -0.485 & -1.120 \\
\hline & & $A_{2}$ & 0.148 & 0.017 & 0.020 & 0.000 & 0.000 & 0.000 & 0.000 & -0.210 & -0.460 & -0.557 \\
\hline & & $A_{3}$ & 0.084 & 0.094 & 0.060 & 0.000 & 0.000 & 0.000 & -0.233 & -0.090 & -0.185 & 0.495 \\
\hline & \multirow[t]{3}{*}{$\lambda=2$} & $A_{1}$ & 0.166 & 0.149 & 0.083 & 0.024 & 0.000 & 0.000 & 0.000 & -0.231 & -0.690 & -1.166 \\
\hline & & $A_{2}$ & 0.251 & 0.054 & 0.044 & 0.000 & 0.000 & 0.000 & 0.000 & -0.353 & -0.656 & -0.770 \\
\hline & & $A_{3}$ & 0.189 & 0.173 & 0.122 & 0.000 & 0.000 & 0.000 & -0.362 & -0.416 & -0.336 & -0.322 \\
\hline \multirow[t]{6}{*}{$Z_{3}$} & \multirow[t]{3}{*}{$\lambda=1$} & $A_{1}$ & 0.011 & 0.000 & 0.000 & 0.000 & 0.000 & -0.048 & -0.086 & -0.433 & -0.575 & -0.830 \\
\hline & & $A_{2}$ & 0.140 & 0.065 & 0.052 & 0.011 & 0.003 & 0.000 & 0.000 & -0.224 & -0.298 & -0.734 \\
\hline & & $A_{3}$ & 0.110 & 0.094 & 0.065 & 0.012 & 0.000 & 0.000 & 0.000 & 0.000 & -0.083 & -0.218 \\
\hline & \multirow[t]{3}{*}{$\lambda=2$} & $A_{1}$ & 0.031 & 0.000 & 0.000 & 0.000 & 0.000 & -0.137 & -0.203 & -0.711 & -0.709 & -1.002 \\
\hline & & $A_{2}$ & 0.179 & 0.179 & 0.105 & 0.029 & 0.015 & 0.000 & 0.000 & -0.319 & -0.473 & -0.790 \\
\hline & & $A_{3}$ & 0.216 & 0.156 & 0.142 & 0.039 & 0.000 & 0.000 & 0.000 & 0.000 & -0.190 & -0.343 \\
\hline
\end{tabular}

Table 11 Comprehensive dominance degree in different $Z_{i}$ and $\lambda$

\begin{tabular}{llllllll}
\hline State & $\lambda$ & $\phi\left(A_{1}, A_{+}\right)$ & $\phi\left(A_{2}, A_{+}\right)$ & $\phi\left(A_{3}, A_{+}\right)$ & $\phi\left(A_{1}, A_{-}\right)$ & $\phi\left(A_{2}, A_{-}\right)$ & $\phi\left(A_{3}, A_{-}\right)$ \\
\hline$Z_{1}$ & $\lambda=1$ & -1.661 & -0.941 & -1.151 & 0.206 & 0.187 & 0.132 \\
& $\lambda=2$ & -2.368 & -1.163 & -1.474 & 0.400 & 0.450 & 0.242 \\
$Z_{2}$ & $\lambda=1$ & -1.695 & -1.227 & -1.002 & 0.196 & 0.185 & 0.238 \\
& $\lambda=2$ & -2.086 & -1.778 & -1.437 & 0.422 & 0.349 & 0.484 \\
$Z_{3}$ & $\lambda=1$ & -1.973 & -1.255 & -0.301 & 0.011 & 0.271 & 0.282 \\
& $\lambda=2$ & -2.762 & -1.583 & -0.533 & 0.031 & 0.506 & 0.553 \\
\hline
\end{tabular}

Table 12 Overall dominance value in different $Z_{i}$ and $\lambda$

\begin{tabular}{lllll}
\hline State & $\lambda$ & $\Phi\left(A_{1}\right)($ Rank $)$ & $\Phi\left(A_{2}\right)($ Rank $)$ & $\Phi\left(A_{3}\right)($ Rank $)$ \\
\hline$Z_{1}$ & $\lambda=1$ & $0.000(3)$ & $1.000(1)$ & $0.622(2)$ \\
& $\lambda=2$ & $0.000(3)$ & $1.000(1)$ & $0.587(2)$ \\
$Z_{2}$ & $\lambda=1$ & $0.000(3)$ & $0.622(2)$ & $1.000(1)$ \\
& $\lambda=2$ & $0.000(3)$ & $0.331(2)$ & $1.000(1)$ \\
$Z_{3}$ & $\lambda=1$ & $0.000(3)$ & $0.503(2)$ & $1.000(1)$ \\
& $\lambda=2$ & $0.000(3)$ & $0.601(2)$ & $1.000(1)$ \\
\hline
\end{tabular}

the development of the emergency, recognizing the fluidity of such events. At the end, the novelty of this paper has been demonstrated by the background of the Tianjin
Port fire and explosion accident. This paper, therefore, contributes to probabilistic hesitant fuzzy set EDM research in attempting to model the dynamics and uncertainty of the external environment. However, the proposed method has a limitation, that is, the mathematical model of probabilistic hesitant fuzzy numbers cannot yet be universally applied to other types of fuzzy decision-making problems. Several future research directions are put forward: (1) other decision-making methods in the context of PFHSs can be tested such as the LINMAP method, and (2) new aggregation operators based on PFHSs is another direction. 


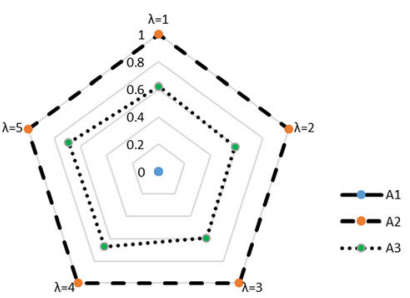

The radar diagram showing the result of the different parameter $\lambda$ in status $Z_{1}$

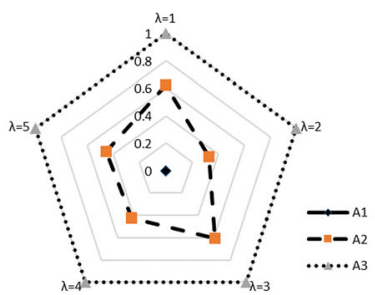

The radar diagram showing the result of the different parameter $\lambda$ in status $Z_{2}$

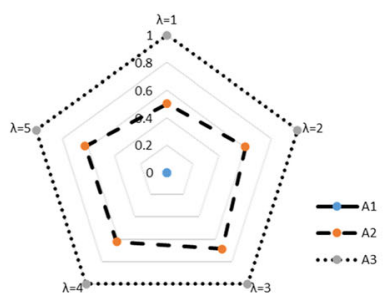

The radar diagram showing the result of the different parameter $\lambda$ in status $Z_{3}$

Fig. 4 Ranking outcomes of parameter $\lambda$ for state $Z_{i}$

Table 13 The overall dominance value using another method [29]

\begin{tabular}{lllll}
\hline State & $\lambda$ & $\Phi\left(A_{1}\right)($ Rank $)$ & $\Phi\left(A_{2}\right)($ Rank $)$ & $\Phi\left(A_{3}\right)($ Rank $)$ \\
\hline$Z_{1}$ & $\lambda=1$ & $0.862(2)$ & $1.000(1)$ & $0.000(3)$ \\
& $\lambda=2$ & $0.754(2)$ & $1.000(1)$ & $0.000(3)$ \\
$Z_{2}$ & $\lambda=1$ & $0.166(2)$ & $1.000(1)$ & $0.000(3)$ \\
& $\lambda=2$ & $1.000(1)$ & $0.129(2)$ & $0.000(3)$ \\
$Z_{3}$ & $\lambda=1$ & $0.000(3)$ & $0.047(2)$ & $1.000(1)$ \\
& $\lambda=2$ & $0.003(2)$ & $0.000(3)$ & $1.000(1)$ \\
\hline
\end{tabular}

Table 14 Comparison results between the method in [29] and the proposed method

\begin{tabular}{llll}
\hline State & $\lambda$ & The method in [29] & The method proposed in this paper \\
\hline$Z_{1}$ & $\lambda=1$ & $A_{2}>A_{1}>A_{3}$ & $A_{2}>A_{3}>A_{1}$ \\
& $\lambda=2$ & $A_{2}>A_{1}>A_{3}$ & $A_{2}>A_{3}>A_{1}$ \\
$Z_{2}$ & $\lambda=1$ & $A_{2}>A_{1}>A_{3}$ & $A_{3}>A_{2}>A_{1}$ \\
& $\lambda=2$ & $A_{1}>A_{2}>A_{3}$ & $A_{3}>A_{2}>A_{1}$ \\
$Z_{3}$ & $\lambda=1$ & $A_{3}>A_{2}>A_{1}$ & $A_{3}>A_{2}>A_{1}$ \\
& $\lambda=2$ & $A_{3}>A_{1}>A_{2}$ & $A_{3}>A_{2}>A_{1}$ \\
\hline
\end{tabular}

Table 15 The overall dominance value using another method [31]

\begin{tabular}{lllll}
\hline State & $\lambda$ & $\Phi\left(A_{1}\right)($ Rank $)$ & $\Phi\left(A_{2}\right)($ Rank $)$ & $\Phi\left(A_{3}\right)($ Rank $)$ \\
\hline$Z_{1}$ & $\lambda=1$ & $0.000(3)$ & $0.470(2)$ & $1.000(1)$ \\
& $\lambda=2$ & $0.000(3)$ & $1.000(1)$ & $0.082(2)$ \\
$Z_{2}$ & $\lambda=1$ & $0.837(2)$ & $0.000(3)$ & $1.000(1)$ \\
& $\lambda=2$ & $0.286(2)$ & $0.000(3)$ & $1.000(1)$ \\
$Z_{3}$ & $\lambda=1$ & $0.000(3)$ & $1.000(1)$ & $0.329(2)$ \\
& $\lambda=2$ & $0.231(2)$ & $1.000(1)$ & $0.000(3)$ \\
\hline
\end{tabular}


Table 16 Comparison results between the method in [31] and proposed method

\begin{tabular}{llll}
\hline State & $\lambda$ & The method in [31] & The method proposed in this paper \\
\hline$Z_{1}$ & $\lambda=1$ & $A_{3}>A_{2}>A_{1}$ & $A_{2}>A_{3}>A_{1}$ \\
& $\lambda=2$ & $A_{2}>A_{3}>A_{1}$ & $A_{2}>A_{3}>A_{1}$ \\
$Z_{2}$ & $\lambda=1$ & $A_{3}>A_{1}>A_{2}$ & $A_{3}>A_{2}>A_{1}$ \\
& $\lambda=2$ & $A_{3}>A_{1}>A_{2}$ & $A_{3}>A_{2}>A_{1}$ \\
$Z_{3}$ & $\lambda=1$ & $A_{2}>A_{3}>A_{1}$ & $A_{3}>A_{2}>A_{1}$ \\
& $\lambda=2$ & $A_{2}>A_{1}>A_{3}$ & $A_{3}>A_{2}>A_{1}$ \\
\hline
\end{tabular}

Acknowledgements This research are supported by the National Natural Science Foundation of China under the grant No. 61773123 and No. 71801050. The authors also would like to express appreciation to reviewers and editors for their very helpful comments on improving the paper.

\section{References}

1. Elmas, C., Sönmez, Y.: A data fusion framework with novel hybrid algorithm for multi-agent Decision Support System for Forest Fire. Expert. Syst. Appl. 38(8), 9225-9236 (2011)

2. Chang, Y., Zhu, Z., Bu, R., Li, Y., Hu, Y.: Environmental controls on the characteristics of mean number of forest fires and mean forest area burned (1987-2007) in China. For. Ecol. Manage. 356, 13-21 (2015)

3. Liang, Y., Tu, Y., Ju, Y., Shen, W.: A multi-granularity proportional hesitant fuzzy linguistic TODIM method and its application to emergency decision making. Int. J. Disaster. Risk. Reduct. 36, 101081 (2019)

4. Ma, Z., Zhu, J., Ponnambalam, K., Zhang, S.: A clustering method for large-scale group decision-making with multi-stage hesitant fuzzy linguistic terms. Inf. Fusion. 50, 231-250 (2019)

5. Hao, Z., Xu, Z., Zhao, H., Fujita, H.: A dynamic weight determination approach based on the intuitionistic fuzzy Bayesian network and its application to emergency decision making. IEEE. Trans. Fuzzy Syst. 26(4), 1893-1907 (2017)

6. Trivedi, A.: A multi-criteria decision approach based on DEMATEL to assess determinants of shelter site selection in disaster response. Int. J. Disaster. Risk. Reduct. 31, 722-728 (2018)

7. Xu, Y., Wen, X., Zhang, W.: A two-stage consensus method for large-scale multi-attribute group decision making with an application to earthquake shelter selection. Comput. Ind. Eng. 116, 113-129 (2018)

8. Li, M.Y., Cao, P.P.: Extended TODIM method for multi-attribute risk decision making problems in emergency response. Comput. Ind. Eng. 135, 1286-1293 (2019)

9. Wang, L., Wang, Y.M., Martínez, L.: A group decision method based on prospect theory for emergency situations. Inf. Sci. 418, 119-135 (2017)

10. Wang, L., Zhang, Z.X., Wang, Y.M.: A prospect theory-based interval dynamic reference point method for emergency decision making. Expert. Syst. Appl. 42(23), 9379-9388 (2015)

11. Xu, X., Huang, Y., Chen, K.: Method for large group emergency decision making with complex preferences based on emergency similarity and interval consistency. Nat. Hazards. 1-20, 97 (2019)
12. Xu, X., Du, Z., Chen, X., Cai, C.: Confidence consensus-based model for large-scale group decision making: a novel approach to managing non-cooperative behaviors. Inf. Sci. 477, 410-427 (2019)

13. Gul, M., Guneri, A.F.: A comprehensive review of emergency department simulation applications for normal and disaster conditions. Comput. Ind. Eng. 83, 327-344 (2015)

14. Zheng, X., Cheng, Y.: Modeling cooperative and competitive behaviors in emergency evacuation: a game-theoretical approach. Comput. Math. Appl. 62(12), 4627-4634 (2011)

15. Amailef, K., Lu, J.: Ontology-supported case-based reasoning approach for intelligent $\mathrm{m}$-Government emergency response services. Decis. Support. Syst. 55(1), 79-97 (2013)

16. Basu, S., Roy, S., DasBit, S.: A post-disaster demand forecasting system using principal component regression analysis and casebased reasoning over smartphone-based DTN. IEEE. Trans. Eng. Manage. 66(2), 224-239 (2018)

17. Xing, H.: The decision method of emergency supplies collection with fuzzy demand constraint under background of sudden disaster. Nat. Hazards. 85(2), 869-886 (2017)

18. Kahneman, D., Tversky, A.: Prospect theory: an analysis of decision under risk. Econometrica. 47(2), 363-391 (1979)

19. Abdellaoui, M., Bleichrodt, H., Paraschiv, C.: Loss aversion under prospect theory: a parameter-free measurement. Manage. Sci. 53(10), 1659-1674 (2007)

20. Gomes, L., Lima, M.: TODIM: Basics and application to multicriteria ranking of projects with environmental impacts. Foundat. Comput. Decis. Sci. 16(4), 113-127 (1992)

21. Sang, X., Liu, X.: An interval type-2 fuzzy sets-based TODIM method and its application to green supplier selection. J. Oper. Res. Soc. 67(5), 722-734 (2016)

22. Qin, Q., Liang, F., Li, L., Chen, Y.W., Yu, G.F.: A TODIM-based multi-criteria group decision making with triangular intuitionistic fuzzy numbers. Appl. Soft. Comput. 55, 93-107 (2017)

23. Geng, Y., Liu, P., Teng, F., Liu, Z.: Pythagorean fuzzy uncertain linguistic TODIM method and their application to multiple criteria group decision making. J. Intell. Fuzzy. Syst. 33(6), 3383-3395 (2017)

24. Jiang, Y., Liang, X., Liang, H.: An I-TODIM method for multiattribute decision making with interval numbers. Soft. Comput. 21(18), 5489-5506 (2017)

25. Zhang, Y., Xu, Z., Liao, H.: Water security evaluation based on the TODIM method with probabilistic linguistic term sets. Soft. Comput. 23(15), 6215-6230 (2019)

26. Qin, J., Liu, X., Pedrycz, W.: An extended TODIM multi-criteria group decision making method for green supplier selection in interval type-2 fuzzy environment. Eur. J. Oper. Res. 258(2), 626-638 (2017) 
27. Zhang, S., Xu, Z.S., He, Y.: Operations and integrations of probabilistic hesitant fuzzy information in decision making. Inf. Fusion. 38, 1-11 (2017)

28. Xu, Z., Zhou, W.: Consensus building with a group of decision makers under the hesitant probabilistic fuzzy environment. Fuzzy. Optim. Decis. Mak. 16(4), 481-503 (2017)

29. Gao, J., Xu, Z., Liao, H.: A dynamic reference point method for emergency response under hesitant probabilistic fuzzy environment. Int. J. Fuzzy. Syst. 19(5), 1261-1278 (2017)

30. Shannon, C.E.: A mathematical theory of communication. Bell. Syst. Tech. J. 27(3), 379-423 (1948)

31. Zhang, X., Xu, Z.: The TODIM analysis approach based on novel measured functions under hesitant fuzzy environment. Knowledge-Based. Syst. 61, 48-58 (2014)

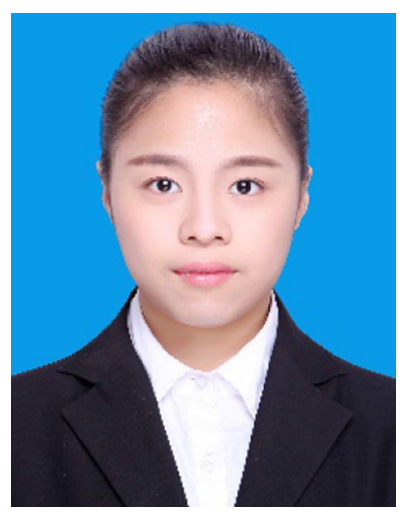

Quanyu Ding is currently working toward the Ph.D. degree in the Fuzhou University, China. Her current research intents include aggregation operators, fuzzy decision making and emergency decision making.

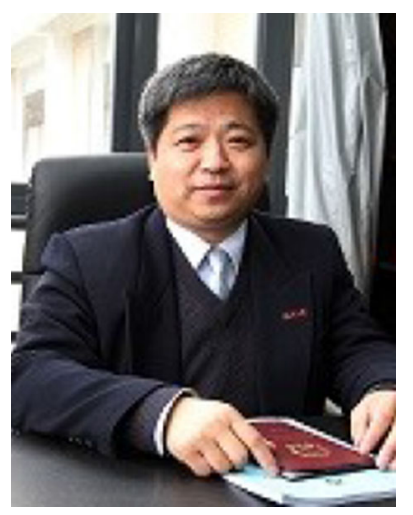

Ying-Ming Wang received the B.S. degree in industrial electrical automation from Jiangsu University, Jiangsu, China, in 1984, and the M.S. degree in system engineering from Huazhong University of Science and Technology in 1987 and the $\mathrm{Ph} . \mathrm{D}$. degree in automatic control theory and application from Southeast University in 1991. $\mathrm{He}$ worked as a postdoctoral fellow in the Department of Environmental Engineering, Tsinghua University from 1991 to 1993 . From 1993 to 2001, he joined in Department of Automation

and Department of Management Science, Xiamen University, where he served as associate professor, professor and doctoral supervisor successively. Then, he was the Senior Fellow in the Department of Systems Engineering and Engineering Management, University of Manchester Business School, UK, and City University of Hong Kong. Since 2009, he has joined the School of Public Administration of Fuzhou University. Yingming Wang have received the following honors and rewards: a distinguished professor of "Minjiang Scholar" of Fujian Province from 2009, a distinguished professor of "Yangtze River Scholar" from 2010, outstanding returnees from overseas studies in Fujian Province in 2012, the national "Millions of Talents Project" from 2012, the leader of universities in Fujian Province from 2013, "High Cited Chinese Researchers" from 2014 to 2018. He has published over 127 SCI and 39 SSCI-indexed journal papers. His research interests include Decision Theory and Method, Data Envelopment Analysis, Rule Base Reasoning, Quality Function Deployment.

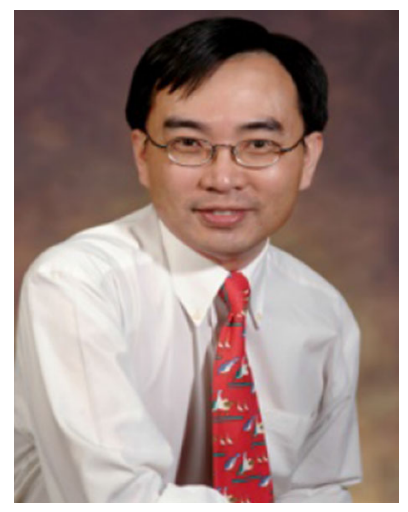

ment, and supply chain strategy.
Mark Goh received the Ph.D. degree in applied mathematics from the University of Adelaide, Australia, in 1987. He is the Director (Industry Research) at the Logistics Institute-Asia Pacific, National University of Singapore, Singapore, where he is a Standing Faculty Member with the School of Business. He is also a Professor at RMIT University, Vic., Australia. His current research interests include buyer-seller relationships, performance measure- 